\title{
Lying is ethical, but honesty is the best policy: Introducing and testing a theory of moral error avoidance
}

\author{
Sarah Jensen ${ }^{* \mathrm{c}}$, Emma Levine ${ }^{*^{\mathrm{a}}}$, Michael W. White* ${ }^{\mathrm{b}}$, Elizabeth Huppert ${ }^{\mathrm{a}}$ \\ *the first three authors are listed alphabetically and contributed equally \\ ${ }^{a}$ The University of Chicago Booth School of Business \\ ${ }^{\mathrm{b}}$ Columbia Business School \\ ${ }^{\mathrm{c}}$ David Eccles School of Business
}

Address correspondence to Emma E. Levine, Associate Professor of Behavioral Science, The University of Chicago Booth School of Business. Email: Emma.Levine@chicagobooth.edu, Phone: 773-834-2861. We are grateful for feedback from Jonathan Berman, Nicholas Herzog, Justin Landy, members of the HOPE lab at the University of Chicago and attendees of the Booth Behavioral Science faculty brown bag. We are grateful for research assistance from Solomon Lister and Jordyn Schor. This research was supported by the Charles E. Merrill Faculty Research Award at the University of Chicago Booth School of Business, awarded to Emma Levine. Chicago Booth's Center for Decision Research labs helped with data collection. All data, syntax, and materials are available at: https://tinyurl.com/HWOL-OSF. 
HONESTY AND MORAL ERROR AVOIDANCE 1

\title{
Lying is ethical, but honesty is the best policy: Introducing and testing a theory of moral error avoidance
}

\begin{abstract}
People claim that honesty is the best policy, while also believing that dishonesty is sometimes ethical. In this article, we introduce and test a theory of moral error avoidance to explain these seemingly inconsistent beliefs. Specifically, we propose that the preference for unconditional honesty is driven by the desire to minimize moral error. We build on classic research on error management theory (Haselton \& Buss, 2000) to explain how the asymmetric costs of harmful lies, versus prosocial lies, lead people to engage in, and reward, others who engage in unconditional honesty. Even though prosocial lies are seen as more moral than harmful truths, the primary error people seek to avoid is telling harmful lies. Through four focal experiments, we test the key predictions of a moral error avoidance account. We also discuss the results of ten additional experiments that test the robustness of our effect and rule out alternative explanations (see supplemental online materials for details; total studies preregistered $=13$ ). We conclude by discussing the implications of moral error avoidance for honesty and moral judgment. Overall, this research provides a holistic understanding of how people think about honesty, helps explain and bridge a number of recent developments in moral psychology, and ultimately sheds light on the overarching purpose of moral rules.
\end{abstract}

Abstract word count: 212

Keywords: honesty, deception, moral judgment, error management, information-avoidance 
HONESTY AND MORAL ERROR AVOIDANCE 2

\section{Introduction}

Honesty is a fundamental moral value. Its importance, emphasized across cultures and religions, is central to both moral identity and interpersonal judgment (Goodwin, Piazza, \& Rozin, 2014). Honesty, for example, is the second most important trait for determining interpersonal liking (ranking slightly below the closely related trait of sincerity; Anderson, 1968). Additionally, decisions involving honesty and dishonesty are among the most common moral decisions we make in everyday life. Honesty is the second most relevant value to the moral acts people encounter in everyday life (falling only behind care), and dishonesty is the third most relevant value to the immoral acts people encounter in everyday life (falling behind harm and unfairness; Hofmann et al., 2014).

Despite honesty’s prominence in moral judgment and everyday decision-making, the psychology of honesty remains elusive. Public figures and ethicists tend to make sweeping generalizations about the importance of honesty (Blanton, 2005; Dalio, 2017; Harris, 2013). Even though most people lie frequently (DePaulo et al., 1996) and privately hold quite nuanced views of honesty (i.e., they believe that lying is sometimes more ethical than honesty; Levine, 2021), they tend to take absolute stances in public (e.g., claiming that lying is never ethical) and reward others who do the same (Huppert et al., 2021). The inconsistency between how people talk about honesty publicly and how they engage in it privately presents a challenge for understanding the moral judgment of honesty.

The moral judgment of honesty is also misunderstood because empirical research has examined a relatively narrow range of honest and dishonest behaviors. A large body of research in behavioral ethics, organizational behavior, and economics has explored when and why people cheat, steal, and lie for personal gain. In this work, dishonesty is confounded with selfishness and 
HONESTY AND MORAL ERROR AVOIDANCE 3

honesty with prosociality (e.g., Gino \& Galinsky, 2012; Lee et al., 2019; Mazar \& Ariely, 2006;

Mazar et al., 2008). This body of research provides enormous insight into the causes of selfish dishonesty and the destructive consequences thereof. However, it provides little insight into how people think about honesty itself and how people navigate more complex dilemmas between honesty and other moral values. An emerging body of research on morally-motivated lies (e.g., Weisel \& Shalvi, 2015; Levine \& Schweitzer, 2015; Hildreth et al., 2016) has begun to address this gap, but is still limited in its focus on single acts of (dis)honesty. Recent work in moral psychology has been similarly focused on how people make sense of specific moral acts, largely concluding that the judgment of moral acts boils down to concerns about harm (e.g., Gray et al., 2014; Schein \& Gray, 2018). People seem quite willing to justify and engage in specific acts of deception, particularly when they perceive these acts as preventing harm (Levine, 2021), but this propensity is difficult to reconcile with the degree to which people endorse honesty as a policy (i.e., as a value that should be followed across time and circumstances).

In the present article, we develop and test a novel theory that explains the apparent inconsistency between preferences for honesty as an absolute policy and preferences for honesty as it applies to individual acts. In doing so, we develop our fundamental understanding of honesty and suggest promising avenues for future research in moral psychology. We propose that the preference for a policy of absolute honesty stems from the desire to minimize moral error. We apply error management theory (Haselton \& Buss, 2000) to the psychology of honesty to explain how the asymmetric costs of harmful lies versus prosocial lies leads people to engage in and reward others who engage in absolute honesty. Even though people view prosocial lies as more ethical than harmful truths, the primary error they seek to avoid is telling harmful lies. When examining honesty in context, with full information about its costs and benefits, people 
HONESTY AND MORAL ERROR AVOIDANCE 4

often believe that lying is more ethical than honesty. However, when considering what policies people should adopt when approaching situations under uncertainty, people endorse a policy of absolute honesty. Absolute moral policies ensure that people do not commit the costliest moral error.

We begin by reviewing recent research that examines judgments of, and reactions to, specific acts of (dis)honesty. This body of work reveals that although harmful lies are seen as substantially less ethical than prosocial truths, prosocial lies are often seen as more ethical than selfish, harmful truths. In other words, the judgment of honesty depends on its consequences. We then review an emerging body of work suggesting that people also have a seemingly contradictory preference for policies of absolute honesty. Finally, we introduce and test a theory of moral error avoidance to integrate and explain these two sets of findings. We present the results of four focal experiments and briefly discuss the results of ten additional experiments and a meta-analysis that tests robustness and rules out alternative explanations (which we report in detail in our supplemental online materials).

We conclude by discussing the implications of moral error avoidance for understanding the psychology of honesty and moral judgment more broadly. Ultimately, this research provides a holistic understanding of how people think about honesty, one of the most fundamental moral values in everyday life. Importantly, this work also helps bridge and explain a number of recent developments in moral psychology. Recent theories of moral judgments argue for (at least) two distinct characterizations of how people approach moral decisions. Whereas some scholars have suggested that lay people are best described as intuitive deontologists (e.g., Everett et al., 2016; Greene, 2007; Jordan et al., 2016; Greene et al., 2001), others have suggested they are best described as intuitive virtue-ethicists (e.g., Landy \& Uhlman, 2018; Critcher et al., 2020). Our 
HONESTY AND MORAL ERROR AVOIDANCE 5

account highlights how both of these characterizations hold some truth and how the relevance of different normative lenses for everyday decision-making depends on whether people are evaluating moral actions or moral policies. When judging individual actions, the goal is to optimize moral goodness; however, when judging moral policies - i.e., decision rules that apply to many actions - the goal is to minimize moral error.

\section{Honesty and the Preference for Prosocial lies}

Many honest actions promote social welfare. For example, honestly revealing one’s flaws or mistakes can improve the performance of groups and teams, honestly reporting conflicts of interest can protect consumers across domains, and delivering honest, timely feedback can improve learning and organizational functioning. These actions, which are both honest and prosocial, are generally seen as moral, and those who commit them are valued as social partners. In these situations, honesty is prosocial and lying is, by comparison, harmful. Prosocial honesty is seen as substantially more ethical than harmful lying (Levine \& Schweitzer, 2014), increases trust (Boles et al., 2000, Schweitzer et al., 2006), increases liking (Tyler et al., 2006), improves relationship satisfaction (Lewis \& Saarni, 1993), and elicits positive emotions (Planalp et al., 1988). On the other hand, harmful lies harm trust and relationships, decrease liking, and elicit negative emotions.

Though the majority of existing research on honesty and deception examines the conflict between prosocial truths and harmful lies, an emerging body of research has begun to examine the antecedents and consequences of prosocial lies (see Levine \& Lupoli, 2021 for a review). Children begin to tell prosocial lies at a young age, with many children telling them by age 3 (Talwar et al., 2007). These lies are often socially rewarded. For example, when children are implicitly and explicitly taught to praise gifts that they dislike, they begin to understand the 
societal rewards of prosocial lying. Further, prosocial lying persists into adulthood. Employees inflate their own and others' performances to help their work teams (Hildreth \& Anderson, 2018; Weisel \& Shalvi, 2015; Wiltermuth, 2011), doctors offer false hope to spare patients emotional distress at the end of their lives (Levine et al., 2018), and parents, teachers, and managers offer false praise to motivate others and avoid emotional harm (Jampol \& Zayas, 2021).

Importantly, prosocial lies, unlike harmful lies, are often seen as ethical. Using deception games, Levine \& Schweitzer $(2014,2015)$ find that people who lie are judged to be more ethical than those who tell the truth when lying is associated with a monetary gain for a partner (and by comparison, truth is associated with a monetary cost). These effects are driven by perceptions of benevolent intent. Even when the outcomes associated with deception and honesty are probabilistic and deception ends up causing harm to a partner, lying is rewarded if it clearly signals benevolent intent. Whereas Levine \& Schweitzer (2014) examine prosocial lies in the context of economic games, more recent work has examined how people judge the ethicality of prosocial lies in everyday life. This work finds that most people - including communicators, targets, and third parties - believe deception is ethical when it prevents unnecessary harm to the target (Levine, 2021). Judgments of unnecessary harm hinge on two key judgments: the degree to which truth-telling prevents harm (i.e., emotional pain and suffering) at the moment of communication and the degree to which the truth has long-term instrumental value (i.e., leads to enlightenment, growth or behavioral change). When the truth causes immediate harm and has low instrumental value, deception is perceived to prevent unnecessary harm and therefore is deemed ethical. Using both qualitative and experimental approaches, Levine (2021) established a number of systematic circumstances that elicit judgments of unnecessary harm. For example, if a target is cognitively impaired (e.g., suffers from dementia or is inebriated), if a target is under 
HONESTY AND MORAL ERROR AVOIDANCE 7

momentary duress (e.g., because they are in a state of shock or grief), or if a target can no longer react to truthful information (e.g., because there is no longer time to institute feedback), hurtful truths are perceived to cause unnecessary harm, and therefore, deception is perceived to be ethical. Together, these results suggest that while people value honesty, they also value and reward prosocial lies depending on the situation.

\section{Preferences for Unconditional Honesty}

Despite people’s preference for prosocial lies, claims that "honesty is the best policy" abound. Why? In general, firm moral stances signal one's commitment to the principle in question, which can be beneficial for trust and character evaluations (Zlatev, 2019; Van Zant \& Moore, 2015). Communicating strong moral stances also helps to disseminate and reinforce moral rules in society. Conversely, admitting that moral rules are flexible sends a signal that a person has lower moral standards and creates ambiguity around the "right” way to behave.

These dynamics influence communication surrounding honesty. Communicators who take unconditional (absolute) stances on honesty (e.g., by saying that "it is never okay to lie”) are seen as more likely to be honest in the future than communicators who take more flexible stances (e.g., by saying that "it is sometimes okay to lie”). As a result, communicators who take unconditional stances on honesty are seen as more moral, even by those who disagree with the stance (Huppert et al., 2021). Preferences for unconditional stances on honesty are strong enough to offset any associated costs of hypocrisy. Even when two communicators go on to tell selfish lies, people tend to view the communicator who took an unconditional (yet hypocritical) stance as more moral and trustworthy than a communicator who took a flexible (yet consistent) stance. Although previous research on hypocrisy suggests that word-deed misalignment entirely undermines the signal of one’s initial words (Jordan et al., 2017), this does not appear to be the 
HONESTY AND MORAL ERROR AVOIDANCE 8

case when discussing honesty. Unconditional endorsement of honesty is viewed as a credible signal of one's likelihood to be honest in the future, even when communicators violate their stance by engaging in deception (Huppert et al., 2021).

The preference for unconditional honesty is not only evident in people’s preference for absolute moral stances but also in communicators’ behaviors. Using similar methods to those employed in the present manuscript, Levine \& Munguia Gomez (2020) found that communicators who did not know how their honesty would affect others often chose to follow a rule of unconditional honesty, rather than seeking out information about the social consequences of their honesty (Study 4). In their paradigm, participants knew that honestly reporting the outcome of a coin flip would lead to a monetary bonus for themselves and their partner. However, participants did not know the value of their partner's monetary bonus and therefore whether the honest report would help or harm their partner. Even though finding out this information was costless for the participant, almost $75 \%$ of participants chose not to find out this information. Instead, they chose to be unconditionally honest without considering how their honesty affected their partner. In a follow-up study, using a modified paradigm in which participants' own bonuses were not at stake, more than $40 \%$ of communicators chose to communicate honestly, rather than obtaining costless information about how their honesty affected a partner. (Levine \& Munguia Gomez, 2020; Study 5). Taken together, these findings suggest that communicators often choose to engage in unconditional honesty and reward others who endorse unconditional claims, despite also believing that prosocial lies are ethical.

\section{Introducing a Theory of Moral Error Avoidance}

In the present research, we seek to explain this apparent paradox. To do so, we apply the perspective of error management theory (Haselton \& Buss, 2000). If one's goal is to behave 
morally and to avoid harm, one is likely to engage in honest behaviors in many circumstances while also attempting to tell prosocial lies when appropriate. However, there are two types of errors that might occur in pursuit of this goal. First, people may err by telling a harmful truth instead of telling a prosocial lie; and second, people may tell a harmful lie instead of the prosocial truth. We argue that telling a harmful truth is by far the less costly of these two errors. Consider the following example. Imagine that your close colleague asks you to listen to them practice a presentation before an important conference. You listen, and your opinion is that the talk needs a lot of work. The PowerPoint slides are too busy, the figures are poorly formatted, and the logic of the talk does not make sense. At the end of the talk, your colleague asks if you have any feedback. Your honest assessment is that the talk needs to be completely reworked, but you know that the talk is in one hour. Given that your colleague has no time to make changes, you recognize that the truth would probably be of little value and would only cause emotional harm, thereby undermining your colleague's welfare. Although most people believe that lying is more ethical than truth-telling in this case (Levine, 2021), telling the truth is not necessarily unethical. Telling the truth will likely hurt your colleague's feelings, but it conveys a respect for the colleague's autonomy and a prioritization of integrity-based trust. In other words, telling a harmful truth reflects a significant, but small, error.

In contrast, imagine that your colleague has an entire week to make changes. In this case, truth-telling promotes your colleague's welfare whereas lying would undermine their ability to learn and improve their presentation. In this situation, people believe that lying is significantly less ethical than truth-telling, and unethical in absolute terms (e.g., Levine, 2021, Study 2). In other words, telling a harmful lie reflects a significant, large error. Error management theory suggests that in this type of circumstance, when there is a systematic cost asymmetry between 
Type I and Type II errors, evolution favors decision rules that are predictably biased towards committing the less costly error.

Indeed, a careful examination of the trends in past work on the judgment of prosocial lies reveals the suggested cost asymmetry. The perceived advantages of prosocial lies (relative to harmful truths) are smaller than those associated with prosocial truths (relative to harmful lies). Although prosocial lies are seen as more ethical than harmful truths, harmful lies are seen as much more unethical than any other action (see Levine \& Schweitzer, 2014, Study 2). Similarly, when the truth would cause immediate harm and lacks instrumental value (and therefore lying would benefit a target, overall), people do tend to endorse lying over truth-telling. However, this endorsement is relatively modest, with, for example, 51.7\%-73.3\% of people believing deception is more ethical than truth-telling (see Levine, 2021, Study 1). On the other hand, when the truth would not cause immediate harm and does have instrumental value (and therefore lying would harm a target, overall), there is unambiguous endorsement of truth-telling, with only $1.7-6 \%$ of people believing that deception is more ethical than truth-telling. Given this asymmetry, error management theory suggests that evolutionary patterns should favor communicators who err in the direction of telling harmful truths over harmful lies. This could explain why people have an overall preference for unconditional honesty, despite also believing that prosocial lying is ethical.

Empirical support for error management theory originates from research looking at perceptions of sexual intent. People often rely on behavioral cues to determine whether a potential romantic partner is interested in them. However, these cues are not foolproof indicators of underlying interest. For example, if a heterosexual man is interested in a heterosexual woman who happens to be very tired and quiet, but is also interested in him, and the man wrongly interprets the woman's tired demeanor as a signal of disinterest, he might erroneously choose to 
ignore the woman and incur the cost of a missed connection. While this type of error does occur, men are far more likely to err in the opposite direction, and overestimate women's sexual interest in heterosexual relationships (Abbey, 1982; Abbey \& Melby, 1986). Haselton and Buss (2000) explain the tendency for males to overestimate sexual interest as an adaptive bias that considers the asymmetric costs of overreading compared to underreading sexual intent. If a man were to assume sexual interest that was not there, historically, the primary costs were failed time and effort, but if a man were to assume no sexual interest when a woman was interested, then the costs of a missed reproductive opportunity were much greater from an evolutionary perspective. When comparing the costs of missed time to those of missed offspring, it is likely that natural selection would favor men who committed the less costly error and missed time. If social decision making is imperfect and errors are inevitably bound to occur, then natural selection processes should similarly favor those who make the Type I error (i.e., a false-positive) over the Type II error (i.e., a false-negative) in other social contexts. In this way, error management theory has been used to explain uncertain social preferences, from romantic interest to religion to supernatural beliefs (e.g., the costs of not believing in a God that exists are greater than the costs of believing in a God that does not exist; Pascal, 1669/2008; Johnson, 2009).

Across disciplines and domains, error management theory predicts that biases towards Type I errors should occur for any decision that both involves uncertainty and has unequal costs associated with Type I and Type II errors (Haselton \& Buss, 2000). Similarly, in the context of honesty, we argue that decision makers are likely to be biased towards the Type I error of telling harmful truths over the Type II error of telling harmful lies. Harmful truth-telling is viewed more positively than harmful lying, and thus, people are likely to reward and reinforce decision rules that are biased towards Type I errors in trade-offs between honesty and other moral values. 
We illustrate this logic in Figure 1 below. Unconditional honesty - which we refer to as "HWOL” (Honesty-without-looking) - binds communicators to truth-telling, regardless of whether the truth ultimately results in a prosocial (helpful) or antisocial (harmful) outcome. In the context of the earlier example, HWOL involves telling your colleague that the talk needs a lot of work, regardless of whether your colleague has time to make improvements. In contrast, conditional honesty - which we refer to as "Looking" - allows a communicator to condition their choice on the state of the world. In the example, looking would involve finding out whether your colleague has time to improve their talk and conditioning your truth-telling on that information.

Figure 1. “Honesty-without-looking” versus “Looking” Decision Tree

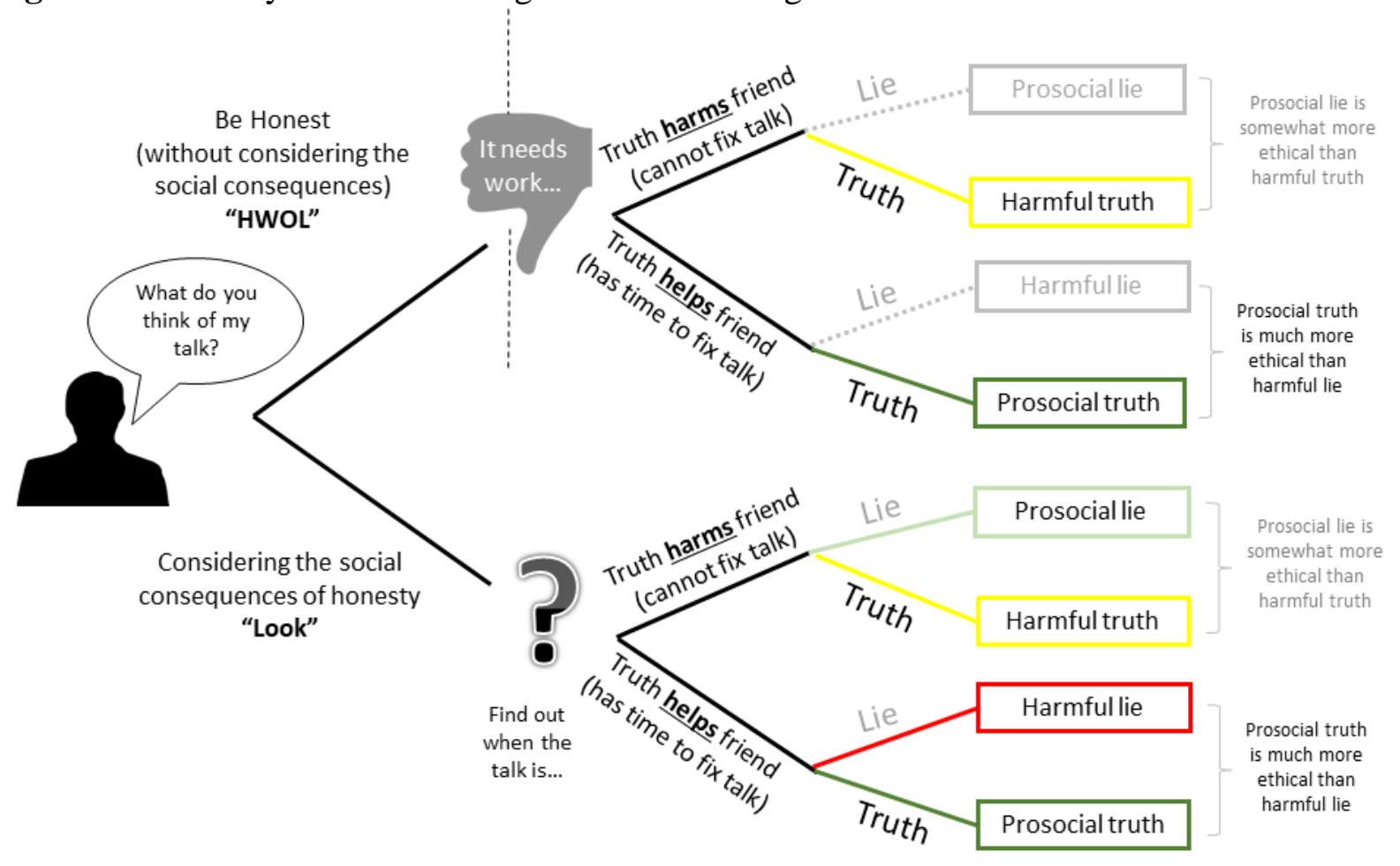

Note. The decision tree specifies the outcomes associated with two decision strategies (HWOL vs. Looking). HWOL binds people to truth-telling, which could lead to a harmful truth or a prosocial truth. Looking gives the decision maker the ability to condition their choice on the social consequences of honesty. 
In the present research, we find that people view HWOL as a more ethical decision strategy than Looking despite the fact that Looking could ensure a prosocial outcome (i.e., a prosocial lie or a prosocial truth). Even though unconditional honesty prevents people from telling prosocial lies, it minimizes overall moral error by preventing people from telling harmful lies. Interestingly, unconditional honesty is rewarded even though it reflects strategic ignorance of the social harm caused by one's communication.

This account helps us understand the preference for honesty, and absolute moral rules more broadly, in the context of ethical dilemmas. A growing body of research on the benefits of “uncalculating cooperation” (Jordan et al., 2016; Hoffman et al., 2015; Capraro \& Kuilder, 2016) finds that actors who cooperate without first finding out the personal consequences of doing so are judged as more trustworthy than actors who find out the personal consequences of cooperation before making their decision. Similarly, taking less time to make a moral decision (Jordan et al., 2016; Critcher et al., 2013) or relying on emotion rather than reason (Barasch et al., 2014; Levine et al., 2018) is perceived to signal morality and trustworthiness, in part, because making intuitive decisions signals low decision conflict and conveys a genuine commitment to moral behavior (Van de Calseyde et al., 2014; Evans \& Van de Calseyde, 2017; Capraro \& Kuilder, 2016).

Scholars have suggested that this body of work can explain why people appreciate unconditional morality writ large, including the decision to unconditionally follow a moral principle, such as the principle of honesty (e.g., Jordan et al., 2016). These effects, however, have only been tested in right-wrong situations; situations in which there is a conflict between following a moral principle and pursuing one’s self-interest. In the uncalculating cooperation paradigm, for example, an actor can cooperate (the moral, prosocial choice) without looking at 
how costly cooperation would be for them, or an actor can first look to see how costly cooperation is, which might tempt them to defect (the immoral, selfish choice; Jordan et al., 2016). An actor would only "look" in this paradigm if they were considering taking the immoral course of action, which presumably signals poor character. In contrast, uncalculating cooperation signals commitment to cooperation, suggesting that a person is not particularly conflicted between helping others and helping themselves.

Beliefs about decision conflict, however, cannot easily explain the preference for moral rule-following in dilemmatic contexts. People experience, and are expected to experience, high decision conflict when faced with ethical dilemmas. (i.e., situations in which there is a conflict between two moral principles; Kidder, 1995; Kohlberg, 1971; Zhang et al., 2018). Furthermore, in the context of honesty-benevolence dilemmas, people often value those who prioritize benevolence over honesty (Levine \& Schweitzer, 2014; 2015). Therefore, existing theories do not provide a clear explanation for why people would prefer unconditional honesty, even when it reflects intentional ignorance of potential social harm. Moral error avoidance does. In rightwrong contexts, following a moral rule minimizes moral error relative to looking for information that could lead to the immoral choice. In dilemmatic contexts, following any moral rule minimizes moral error relative to looking for information that could lead to the most immoral choice.

\section{Overview of research}

We test this account - that moral error avoidance explains the preference for unconditional honesty - across 4 main experiments (as well as 10 supplemental studies), using both economic games and face-valid vignettes. In these studies, we compare moral judgments of two different strategies that people could pursue when faced with a dilemma involving difficult 
truths: 1) "HWOL," which binds people to truth-telling, regardless of whether the truth ultimately helps or harms a target, and 2) "Looking," which allows people to condition their honesty on its social consequences (see Figure 1). Consistent with our account, we find that people judge actors who engage in HWOL as more moral and accord them greater trust than actors who engage in Looking (Studies 1, 2a, and 2b), despite believing that Looking yields morally superior decisions (Studies 2a, 2b, 3, \& 4). In Study 3, we present a key test of the moral error avoidance account. Specifically, we test whether the preference for HWOL attenuates when it is clear that Looking will not result in a moral error (i.e., when it is clear that HWOL will not result in a harmful lie). We also rule out a number of alternative mechanisms (see also Studies S1, S2, S4 \& S8 in SOM 2). Finally, in Study 4, we explore a potential boundary of moral error avoidance, beyond the domain of honesty (for a replication, see Study S5 in SOM 2).

Across our studies, our stopping rules for data collections were decided in advance, and we report all measures and conditions we collected. Based on our past research, we aimed to recruit 100-150 participants per cell in each study. This yielded powers of .68, .82, .93, .99, and.72, to detect our focal effect of morality in Studies 1, 2a, 2b, 3, and 4, respectively. In Studies 1, 3, and 4, we used the observed Cohen's $d$ s for the focal effect of the HWOL versus Looking on perceived morality and used the sample sizes of the relevant conditions for each study (see Table 3 for summary) to compute power using a post-hoc power analysis for independent-samples t-tests with $\alpha=.05$ in $\mathrm{G}^{*}$ power, version 3.1. In Studies $2 \mathrm{a}$ and 2b, we used the observed $z$ statistics for the focal effect of the proportion selecting HWOL as the most ethical decision strategy when the consequences of honesty were known versus unknown to compute power using a post-hoc power analysis for independent-samples z-tests comparing two proportions, with $\alpha=.05$ in $\mathrm{G}^{*}$ power. 
Our reported samples consist of all participants who correctly answered the study comprehension checks and completed the study in its entirety. Participants who did not correctly answer comprehension checks within two attempts were directed to the end of the survey without completing our dependent variables, and therefore, are not included in any analyses. Studies 1, 2b, 3, and 4 were preregistered on aspredicted.org. All data, syntax, and materials are available at: https://tinyurl.com/HWOL-OSF. The Institutional Review Board at the [University name] approved all studies. At the end of each study, participants provided demographic information.

\section{Study 1: Establishing the preference for Unconditional Honesty (HWOL)}

In Study 1, we examine people's judgments of, and behavior towards, communicators who engage in unconditional honesty. Specifically, we examine people's moral judgments of communicators who were either honest without looking at the consequences of honesty ("HWOL”), or who looked at consequences of honesty before deciding whether or not to tell the truth (“Looking”) when playing an economic game. We also examine trust in communicators who engage in HWOL versus Looking by measuring the degree to which participants willingly rely on advice from the communicator, using an adapted Weight of Advice (WOA) Task (Gino \& Schweitzer, 2008).

\section{Method}

Participants. As preregistered (https://aspredicted.org/blind.php?x=z28qq7), we aimed to recruit as many participants as possible in one day from the [university laboratory]. We ended up with a final sample of 240 participants (mean age $=27.39,74 \%$ female).

Procedure and materials. We randomly assigned participants to one of two possible experimental conditions in a 2 (Decision Strategy: HWOL vs. Looking) between-subjects design. 
Participants were first paired with a Communicator and learned that their assigned Communicator previously participated in a study in which they played the Coin Flip Game (adapted from Levine \& Munguia Gomez, 2020). The Communicator's decision in the Coin Flip Game produced a payout that affected a Target (a third party, who was not the focal participant). This game is similar to a traditional deception game (Gneezy, 2005), except that truth-telling and deception did not affect the payoff for the Communicator, and the payoffs for the Target associated with each action were unknown.

In the game, Communicators learned that they would flip a digital coin-which had a 50\% chance of landing on heads and a 50\% chance of landing on tails-and would then report the outcome to the experimenter. Communicators then learned that their report would influence the payment of a partner, but the exact monetary values associated with their report were unknown. Specifically, they read that:

- If you report that the coin landed on HEADS, your partner will receive \$A

- If you report that the coin landed on TAILS, your partner will receive \$B

Although the exact amounts were unknown, Communicators did learn information about the possible values of $\mathrm{A}$ and B. Communicators knew that there was a 50\% chance that \$A was \$1 and \$B was $-\$ 1$, and a 50\% chance that $\$ A$ was $-\$ 1$ and $\$ B$ was $\$ 1$. As a result, the probabilities that telling the truth would help the Target, telling the truth would harm the Target, telling a lie would help the Target, and telling a lie would harm the Target were all equal.

Next, the Communicator flipped the coin. The Communicator then made one of three possible choices: They either selected "The coin landed on HEADS," "The coin landed on TAILS," or "I'd like to find out the values of \$A and \$B before making my decision.” 
Roughly half of the participants in our study learned about a Communicator who honestly reported the outcome of the coin flip without looking at the consequences associated with the decision to tell the truth (HWOL condition). The other half of participants learned about a Communicator who chose to look at the consequences of telling the truth before reporting the outcome (Looking condition). Figure 2 depicts the design of the study.

Figure 2. Design of Study 1

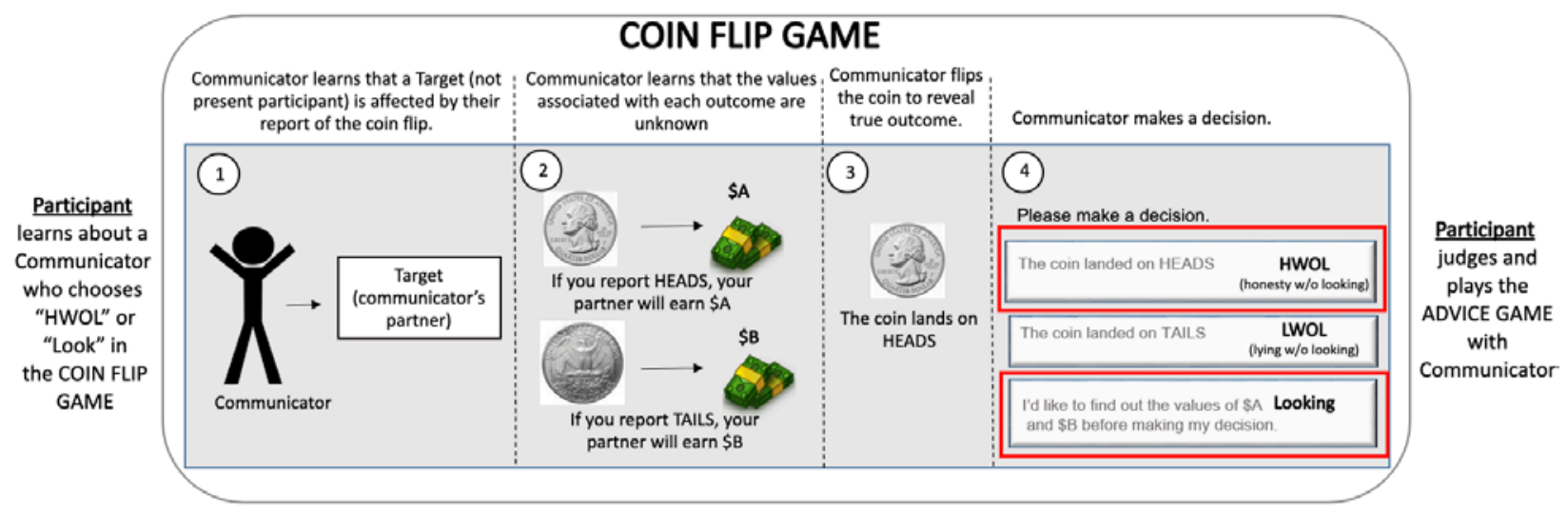

Notes. The figure depicts the experimental design in which participants judged and interacted with communicators that either used the decision strategy of unconditional honesty (HWOL) or sought out more information (Looking) within the Coin Flip Game. Although lying (LWOL) was a possible decision strategy, we are primary interested in how participants evaluated communicators who chose the decision strategies outlined in red.

After learning about the Communicator’s behavior in the Coin Flip Game, participants played the Advice Game with the Communicator. The Advice Game was adapted from the Weight of Advice Task used in Gino \& Schweitzer (2008). In this task, participants made an initial estimate of how much money was in a jar of coins. Then, participants received advice from the Communicator about how much money was in the jar. Participants knew that the Communicator knew the true amount of money in the jar, but they did not know whether the Communicator was incentivized to give truthful or untruthful advice to the participant. After seeing the Communicator's advice, participants had the option to revise their guess before 
reporting the final estimate of how much money they thought was in the jar of coins. If a participant's final estimate was within $\$ 1$ of the true amount of money in the jar of coin, the participant received a bonus.

We calculated weight of advice (WOA) by taking the absolute value of the difference between the participant's final and initial estimates and dividing it by the absolute value of the difference between the amount of the Communicator's advice and the participant's initial estimate. The WOA captures the degree to which the participant's final estimate is anchored on their own initial estimate versus the advice they received from the Communicator; higher numbers reflect greater reliance on the Communicator's advice. In other words, WOA is a continuous measure of the degree to which a person trusts the Communicator's advice. After playing the Advice Game, participants judged the Communicator's morality using a three-item composite of moral, good, and ethical (1= Not at all, 7= Extremely; $\alpha=.944)^{1}$.

\section{Results}

Consistent with our preregistration, we conducted independent samples t-tests on morality and WOA, using Decision Strategy as the independent variable. We find that participants relied on the advice of the Communicator who was honest without looking (HWOL: $M=0.68, S D=0.66$ ) more than the Communicator who looked at the consequences of honesty (Looking: $M=0.52, S D=0.42 ; t(238)=2.37, p=.019$ ). Participants also judged Communicators who were honest without looking as significantly more moral (HWOL: $M=4.37, S D=1.14$ ) than those who looked (Looking: $M=4.06, S D=1.15 ; t(238)=2.12, p=.035$ ). Effect sizes (Cohen's $d$ ) associated with key contrasts in Study 1 and all other studies are reported in Table 3.

\section{Discussion}

\footnotetext{
${ }^{1}$ We also included a measure of perceived trustworthiness. The details of all ancillary measures in our studies are reported in the SOM.
} 
Study 1 provides evidence that people judge unconditional honesty (HWOL) as more moral than conditional honesty (Looking) and are more likely to rely on the advice of communicators who are unconditionally honest. Even though our paradigm clarified that honesty was just as likely to harm as to help a communication partner, and that this uncertainty could have been resolved by choosing to find out the values of $\$ \mathrm{~A}$ and $\$ \mathrm{~B}$, people believed that unconditional honesty was the more ethical decision strategy. We replicate these results in six supplementary studies that explore the robustness of the preference for HWOL across contexts. We discuss these studies in brief in the General Discussion and conduct a meta-analysis of all the experiments our team ran to examine moral judgments of HWOL versus Looking (see also Table 3). All studies are reported in detail in SOM 2.

\section{Study 2: Judgment of Unconditional Honesty in the Context of Negative News}

In Studies 2a and 2b, we examine the preference for unconditional honesty using facevalid vignettes. Importantly, we also extend our investigation by providing more direct evidence of our moral error avoidance account. Specifically, we show that people have both a preference for prosocial lies over harmful truths and a preference for unconditional honesty within the same paradigm. In Study 1, participants may have simply preferred unconditional honesty (HWOL) because they failed to consider whether deception would be more moral than honesty if the truth did indeed cause harm. In Study 2, we demonstrate that people prefer unconditional honesty, even when they realize that deception is sometimes more moral than truth-telling. Study 2a was conducted between-subjects and features a scenario about providing negative feedback. Study $2 \mathrm{~b}$ is a preregistered conceptual replication of Study 2a that utilizes a within-subjects design and a field sample. It features a scenario about revealing an act of infidelity.

\section{Study 2a Method}


Participants. We recruited 199 participants (mean age $=35.87,40 \%$ female) from Amazon Mechanical Turk (MTurk).

Procedure and materials. Participants read a scenario about a situation in which a colleague who was about to give an important presentation asked them how s/he looked in an illfitting suit (adapted from Levine, 2021). Participants were randomly assigned to one of two conditions in a between-subjects design; knowledge about the consequences of being honest was either Known or Unknown to the participant (Consequences: Unknown vs. Known).

Participants in the Unknown condition made a single judgment, without knowing the social consequences of honesty. Specifically, they did not know whether the colleague could change their suit (and therefore, did not know whether providing honest critical feedback would ultimately help or harm them). Participants indicated whether the most ethical decision would be to: a) "Tell the employee the truth — saying that he thinks the suit is inappropriate" (this represents HWOL), b) “Lie to the employee — saying that he thinks the suit is fine” (this represents LWOL, Lying without looking), or c) "find out if the employee owns another suit before answering” (this represents Looking). This choice parallels the decision participants faced in Study 1, in which participants judged the morality of a communicator who chose either HWOL or Looking without knowing whether honesty would either help or harm someone else.

Participants in the Known condition were presented with two versions of the same scenario and made two judgments based on these scenarios in a randomized order. Specifically, participants indicated whether lying or truth-telling would be the most ethical choice if they knew that honesty harmed their colleague (i.e., if the colleague could not change their suit) and if they knew honesty helped their colleague (i.e., if the colleague could change their suit). For each judgment, participants indicated whether the most ethical decision was: a) "Tell the employee the 
truth—saying that he thinks the suit is inappropriate" or b) "Lie to the employee—saying he thinks the suit is fine.” The exact text from each condition is reported in SOM 1.2.1.

The purpose of the Known condition was to confirm that participants were facing a situation that would lead them to condition their communication decision on the consequences of honesty, when those consequences were known. Consistent with existing work (Levine, 2021), we expected the majority of participants to indicate that honesty was the ethical choice when honesty helped the target, but to indicate that lying was the ethical choice when honesty caused harm to the target.

Importantly, in the Known condition, we could also calculate the percentage of people who did condition their moral judgments on these social consequences (i.e., by making different communication choices when honesty helped vs. harmed the colleague), implying a preference for Looking.

According to rational decision theory, if information is material to a decision and costless to receive, people should seek it out. In other words, rationally, the percentage of people who condition their choices on the social consequences of honesty in the Known condition should be roughly equal to the percentage of people who choose to find out information about the social consequences of honesty in the Unknown condition. Similarly, the percentage of people who choose honesty in both contexts of the Known condition should be roughly equal to the percentage of people who choose HWOL in the Unknown condition, and the percentage of people who choose lying in both contexts of the Known condition should be roughly equal to the percentage of people who choose LWOL in the Unknown condition. Our main planned analysis was to compare these percentages; that is, we intended to compare the distribution of choices (HWOL, LWOL, Looking) expressed in the Unknown condition to the distribution of choices 
HONESTY AND MORAL ERROR AVOIDANCE 23

implied by the set of decisions in the Known condition. If the distributions are not significantly different, this implies that the preference for HWOL may simply stem from the belief that information about the social consequences of honesty is immaterial. This would imply that people think unconditional honesty is ethical because moral judgments do not depend on the social consequences of honesty. In contrast, if the percentage of people who choose Looking is smaller, and/or the percentage of people who choose HWOL is greater in the Unknown condition than the preferences revealed in the Known condition, it suggests that there must be another mechanism leading people to value unconditional honesty. We propose - and test in Studies 3 and 4 - that this mechanism is moral error avoidance.

\section{Study 2a Results}

In the Known condition, the vast majority (78\%) of participants believed honesty was the most ethical decision when honesty was helpful and deception was harmful. In contrast, when honesty was harmful and deception was helpful, the majority (55\%) of participants believed that deception was the most ethical choice, consistent with prior work on prosocial lies. These frequencies are consistent with the asymmetric costs associated with lying versus truth-telling. Telling a harmful lie is much worse than telling a helpful truth (22\% versus $78 \%$ endorsement, respectively); whereas telling a helpful lie is only somewhat better than telling a harmful truth (55\% versus $45 \%$ endorsement).

Looking at participants’ decisions in the Known condition reveals that $40 \%$ of participants chose the honest option across both situations they faced (implying a preference for HWOL), whereas 44\% conditioned their moral judgments on the consequences of honesty (implying a preference for Looking). 16\% of participants indicated that lying was the most ethical choice in both situations (implying a preference for LWOL). 
However, in the Unknown Condition, the majority (58\%) of participants chose HWOL as the most ethical decision strategy. In contrast, only $29 \%$ of people chose Looking, and $13 \%$ of people chose LWOL. The distribution of choices that implied preferences for HWOL, LWOL, and Looking in the Known condition significantly differed from the actual choices for HWOL, LWOL, and Looking in the Unknown condition, $X^{2}=6.70, p=.035$. Figure 3 depicts these results.

\section{Study 2a Discussion}

Study 2a reveals that people believe that unconditional honesty is the most ethical decision strategy when the communicator does not know whether honesty will help or harm a partner, consistent with Study 1. People believe it is ethical to avoid finding out whether honesty

will cause harm, and instead, to simply tell the truth. However, using the same paradigm, we also show that when people do know that honesty does, or does not, cause harm, people base their ethical beliefs on this information. Consistent with prior work on prosocial lies, people believe that honesty is ethical when it helps the target, but that lying is ethical when honesty harms the target. 
Figure 3. Study 2a and 2b Results

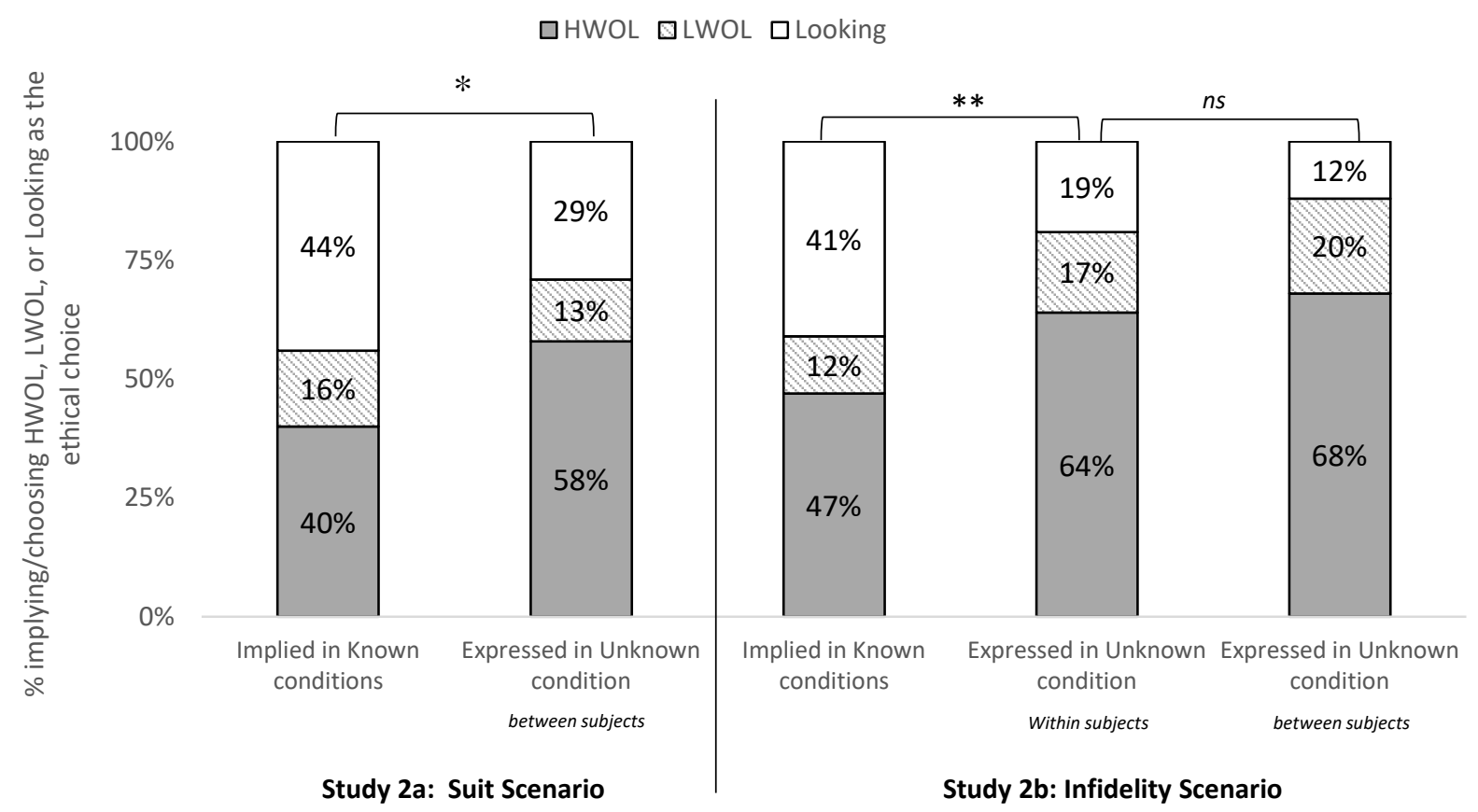

Notes. Even though participants' individual choices often revealed a preference for Looking ("Implied in Known conditions"), the majority of participants indicated that HWOL was the most ethical choice ("Expressed in Unknown condition"). In other words, participants endorsed unconditional honesty, even when they would choose to condition their honesty on its social consequences. These effects persisted both between- (Study 2a) and within- (Study 2b) subjects, and across multiple contexts. * signifies $p<.05$; ${ }^{* *}$ signifies $p<.001$.

These results are consistent with the account of moral error avoidance. Though harmful truth-telling was seen as less ethical than prosocial lying, the moral costs of harmful lying were much more seen as more severe than those of harmful truth-telling. We propose that, as a result, people believe that unconditional honesty is the morally preferred strategy. Although unconditional honesty does not optimize moral goodness (Communicators bound to truth-telling cannot tell a prosocial lie), it ensures that a harmful lie is not told, thereby eliminating the greatest moral error. 
HONESTY AND MORAL ERROR AVOIDANCE 26

\section{Study $\mathbf{2 b}$}

We provide further evidence of the moral error avoidance account in Study 2b. Study 2b employs the same basic paradigm, except the Known/Unknown manipulation was conducted within-subjects. This design ensures that the preference for unconditional honesty cannot be explained by a simple failure to think through the relevant decision tree (Shafir \& Tversky, 1992). When the social consequences of honesty are unknown, people may simply fail to consider what they should do if they found out honesty were helpful versus harmful. We rule out this possibility in Study 2b; participants preferred HWOL (to Looking) when consequences were unknown even after they thought through both of these possible outcomes.

\section{Study 2b Method}

Participants. As preregistered (https://aspredicted.org/blind.php?x=3f3g5s), we aimed to recruit 200 adults from local city parks and our behavioral laboratory. We monitored the number of participants we had at the end of each day and stopped once we reached at least 200. We ended up with a final sample of 220 participants (mean age $=36.21 ; 48 \%$ female).

Procedure. Participants were assigned to one of two conditions (Condition:

Consequences-Unknown-Only vs. Consequences-Known-Followed-By-ConsequencesUnknown) in a between-subjects design. The Consequences-Unknown-Only had an identical design to the "Unknown" condition in Study 2a; participants made a single judgment when consequences of honesty were not known. However, a different scenario was used. Participants read about an individual with a life-threatening illness who asked their spouse if they had ever been unfaithful. Consistent with existing work (Levine, 2021), we conceptualized honesty as helpful when the illness was treatable (in which case honesty had instrumental value) and as harmful when the illness was untreatable (in which case honesty had no instrumental value and 
HONESTY AND MORAL ERROR AVOIDANCE 27

only caused emotional harm in the final days of life). Participants in the ConsequencesUnknown-Only condition indicated whether the most ethical decision was to be honest (HWOL) or lie (LWOL) without finding out whether the illness was treatable, or to find out whether the illness was treatable before making a communication decision (Looking).

Participants in the Consequences-Known-Followed-By-Consequences-Unknown condition made three judgments. First, participants made the same two judgments that participants made in the "Known” condition of Study 2a (however, a different scenario was used, as described above). In a randomized order, participants indicated whether lying or truth-telling was the more ethical choice when a) the illness was untreatable (i.e., honesty was harmful); and b) the illness was treatable (i.e., honesty was helpful). Then, after thinking through these two decisions, participants made the same decision participants made in the ConsequencesUnknown-Only condition - choosing between HWOL, LWOL, and Looking. The exact text for each condition is reported in SOM 1.2.2.

\section{Study 2b Results}

When the consequences of honesty were known (In the “Consequences Known” portion of the Consequences-Known-Followed-by-Consequences-Unknown condition), the vast majority (85\%) of participants believed honesty was the most ethical decision when honesty was helpful and deception was harmful. In contrast, when honesty was harmful and deception was helpful, half (50\%) of participants believed that deception was the most ethical choice. A total of $47 \%$ of participants chose honesty across both situations they faced (implying a preference for HWOL), whereas $41 \%$ conditioned their moral judgments on the consequences of honesty (implying a preference for Looking). 12\% of participants indicated that lying was the most ethical choice in both situations (implying a preference for LWOL). 
This distribution of choices, however, significantly differed from the distribution of choices expressed by these same participants when the consequences of honesty were unknown (In the "Consequences Unknown" portion of the Consequences-Known-Followed-byConsequences-Unknown condition; $z=-4.23, p<.001){ }^{2}$ That is, even after thinking through the decisions they would make when honesty was helpful and when honesty was harmful, $64 \%$ of participants still chose HWOL as the most ethical choice when the consequences of honesty were not yet known; 19\% chose Looking and 17\% chose LWOL.

In the Consequences-Unknown-Only condition, 68\% chose HWOL as the most ethical choice, 12\% chose Looking, and 20\% chose LWOL. Consistent with Studies 1 and 2, the majority of participants saw HWOL as the most ethical choice when the consequences of honesty were unknown. The distribution of choices in the "Consequences Unknown" phase of the Consequences-Known-Followed-By-Consequences-Unknown condition did not significantly differ from the distribution of choices in the Consequences-Unknown-Only condition $\left(\chi^{2}=1.96\right.$, $p=.375)$. Figure 3 depicts these results.

\section{Study 2b Discussion}

Study $2 \mathrm{~b}$ suggests that the preference for HWOL is not driven by a failure to think through the decision tree and consider what is most ethical when honesty causes harm. People believe that unconditional honesty is ethical when they the social consequences of honesty are unknown, even after they make judgments about what is most ethical when the consequences are known.

\footnotetext{
${ }^{2}$ We note that our preregistration stated we would use a chi-square test to examine the (implied) distribution of choices within the "Consequences Unknown" and the "Consequences Known" portions of the Consequences-Known-Followed-by-Consequences-Unknown condition. However, given that this was a within-subjects comparison, a chi-square test was not appropriate. We conducted a Wilcoxon Signed Ranks test instead.
} 
HONESTY AND MORAL ERROR AVOIDANCE 29

\section{Study 3: Judgments of Unconditional Honesty After Eliminating the Possibility of Error}

In Study 3, we test a key prediction of the theory of moral error avoidance. We propose that the preference for unconditional honesty is driven by the asymmetric costs associated with lying versus truth-telling. People perceive harmful lies to be a more costly error than harmful truths and therefore endorse moral strategies that prevent them. However, if it is clear that conditional honesty (i.e., Looking) will not lead to harmful lies, the preference for unconditional honesty should be attenuated. We test this in Study 3. Using the same paradigm as Study 1, we manipulate whether Communicators who choose to engage in conditional honesty can precommit to a specific course of action.

\section{Method}

Participants. As preregistered (https://aspredicted.org/blind.php?x=52vw62), we aimed to recruit 800 participants using the Academic Prolific platform. We ended up with a final sample of 770 participants (mean age $=34.66 ; 48 \%$ female).

Procedure and materials. Participants were randomly assigned to a condition from a 2 (Decision Strategy: HWOL vs. Looking) x 2 (Decision Option: Precommitment vs. No Precommitment) between-subjects design. The No Precommitment conditions were conceptually identical to the coin flip game paradigms in Study 1 with two key changes.

First, we changed the possible values of A and B. As in Study 1, participants knew that if they reported that the coin landed on heads, their partner would earn \$A, and if they reported that the coin landed on tails, their partner would earn \$B. In Study 3, however, Communicators knew that there was a $50 \%$ chance that $\$ \mathrm{~A}$ was $\$ 2$ and $\$ \mathrm{~B}$ was $-\$ 5$, and a $50 \%$ chance that $\$ \mathrm{~A}$ was $-\$ 5$ and $\$ \mathrm{~B}$ was $\$ 2$. We determined these possible values of $\mathrm{A}$ and $\mathrm{B}$ based on the results of a small pilot study $(N=35$; mean age $=33.94,57 \%$ female $)$ that examined the threshold at which people 
would endorse a prosocial lie over a harmful truth. Specifically, the pilot participants learned a coin flip landed on heads and that honestly reporting this outcome would result in $-\$ 2$ for another participant. Then, pilot participants reported the minimum value that would make it more ethical to lie about the coin flip outcome than telling the truth (i.e., Imagine the coin landed on Heads. If $\mathrm{A}=-\$ 2.00$, what value of $\$ \mathrm{~B}$ would make it ethical to report tails, rather than heads?) All 35 pilot participants reported it would be more ethical to tell the prosocial lie if B was at least $\$ 5$ when A was -\$2. This pilot confirmed that we created a paradigm in which participants would indeed prefer prosocial lying over harmful truth-telling (as in Studies 2a and 2b), which we did not explicitly test in Study 1.

In Study 3, we also slightly changed the language in the Looking option. Specifically, the option read "I'd like to base my decisions on the values of \$A and \$B." Participants knew that if the Communicator chose this option, they would see the values associated with \$A and \$B and then make their decision (reporting heads or tails), similar to the Looking choice in Study 1.

In the Precommitment condition, we modified the Looking options further. Participants learned that if the Communicator chose "I'd like to base my decisions on the values of \$A and $\$ \mathrm{~B}$,” they would then precommit to decisions for each possible value of $\$ \mathrm{~A}$ and $\$ \mathrm{~B}$. Specifically, they would indicate what they would like to do if $\$ \mathrm{~A}$ turned out to be $\$ 5$ and $\$ \mathrm{~B}$ turned out to be $-\$ 2$, and what they would like to do if $\$ \mathrm{~A}$ turned out to be $-\$ 2$ and $\$ \mathrm{~B}$ turned out to be $\$ 5$. These decisions would then automatically be instituted by the computer, once the true values of $\mathrm{A}$ and B were revealed. 


\section{Figure 4. Stimuli depicting Communicator choices in the Precommitment/Looking condition of Study 3}

First participants saw the instructions for the Precommitment condition and the Communicator's initial choice. The Communicator below selected the Looking option (indicated by blue highlighting).

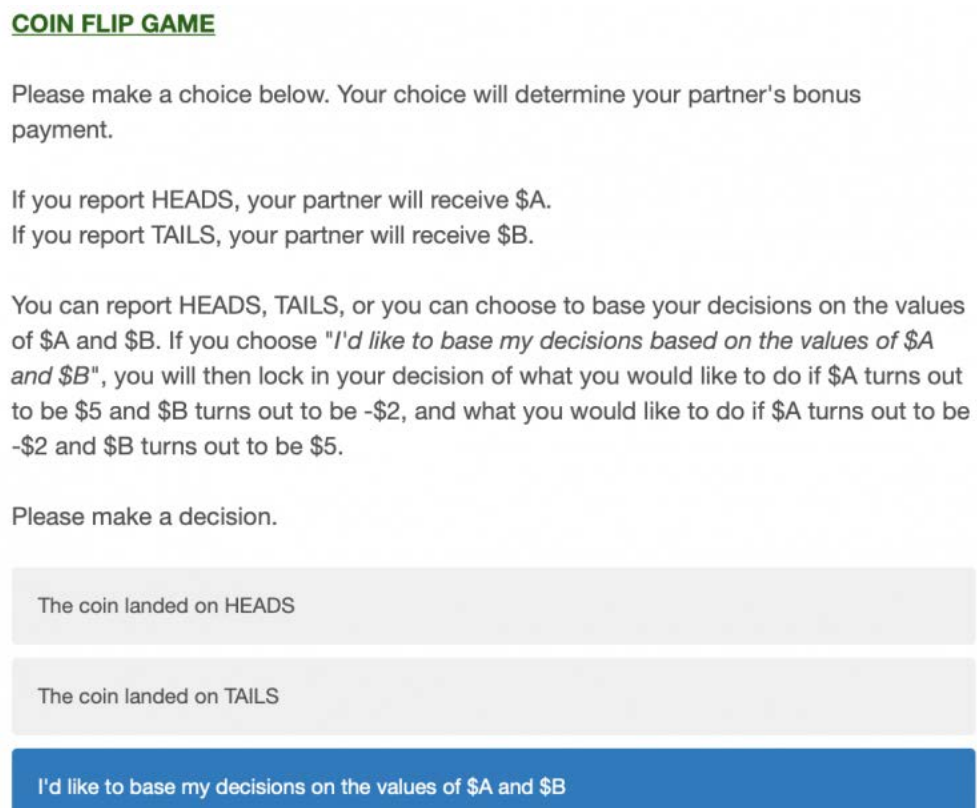

If the Communicator selected the Looking option, participants saw the Communicator's precommitment decisions on the next page. The Communicator always precommitted to the prosocial choices. If the Communicator chose HWOL ("The coin landed on HEADS") on the first screen, no second page was presented.

If $\$ A$ is worth $\$ 5$ and $\$ B$ is worth $-\$ 2 \ldots$

I will report the coin landed on HEADS

(Results in $\$ A=\$ 5$ for the RECEIVER)

I will report the coin landed on TAILS

(Results in $\$ B=-\$ 2$ for the RECEIVER)

If $\$ A$ is worth $-\$ 2$ and $\$ B$ is worth $\$ 5 \ldots$

I will report the coin landed on HEADS

(Results in \$A = -\$2 for the RECEIVER) 
In our Precommitment/Looking condition, participants always learned that the Communicator chose "I'd like to base my decisions on the values of $\$ \mathrm{~A}$ and $\$ \mathrm{~B}$ " and then precommitted to reporting whichever outcome of the coin flip (heads or tails) yielded a $\$ 5$ bonus for their partner. This precommitment reflects conditional honesty, but it also eliminates the possibility of moral error (i.e., telling a harmful lie). Figure 4 depicts the exact text participants saw in the Precommitment/Looking condition. Participants had to pass comprehension checks to confirm they both understood both the Decision Strategy and the Decision Options of the Communicator. Participants who answered a question incorrectly had the chance to review the instructions and answer the questions again. Participants who answered any questions incorrectly on the second try were automatically kicked out of the survey. ${ }^{3}$

\section{Dependent Variables.}

Morality. Our primary dependent variable was the judgments of the Communicator's morality using the same three item composite used in Studies 1 and $2(\alpha=.923)$.

Exploratory Variables. Though we directly manipulated whether conditional honesty could lead to a moral error (a harmful lie) in the present context, it is possible that conditional honesty is troublesome not only because it can immediately lead to harmful lies, but also that it can lead to moral errors in future situations. We measured several exploratory constructs to understand these concerns. All items related to these constructs were measured on seven-point scales $(1=$ Not at all, 7 = Extremely $)$.

\footnotetext{
${ }^{3}$ We note that the nature of the comprehension checks did lead to differential attrition across conditions. Participants were more likely to fail the comprehension checks when they were in the Precommitment condition, leading to somewhat uneven cell sizes. Therefore, it is possible that remaining participants in the Precommitment condition were more thoughtful, attentive participants than those in the No precommitment condition.
} 
HONESTY AND MORAL ERROR AVOIDANCE 33

Tendency to tell Harmful Lies. Participants reported their belief that the Communicator would tell harmful lies outside of the present context, using one-item: "Outside of the context of the Coin Flip Game, to what extent do you think [the Communicator] would tell lies that harm others."

Tendency to tell Helpful Lies. Participants also indicated the extent to which they believe the Communicator would tell helpful lies: "Outside of the context of the Coin Flip Game, to what extent do you think [the Communicator] would tell lies that help others".

Slippery Slope of Deceptive Behavior. Participants also indicated the extent to which they believe the Communicator's behavior will lead to a slippery slope of deceptive behavior in the future (Anderson et al., working paper) using two items: "I'm concerned that [the Communicator's] current behavior may lead them to tell bigger lies in the future," and "I'm concerned that [the Communicator's] current behavior may make it easier for them to justify future lies" $(r(770)=.794)$.

Internalized Moral Standards. We also examined the degree to which conditional honesty undermined judgments of a Communicator's moral standards, independent of (future) lie behavior (Huppert et al., 2021) using three-items: “The [Communicator] would feel guilty if they lied," “The [Communicator] thinks carefully before lying,” and “The [Communicator] genuinely values honesty" $(\alpha=.753)$.

\section{Results}

Morality. A two-way ANOVA on judgments of morality revealed a main effect of Decision Strategy $(F(1,766)=18.96, p<.001)$; Communicators who engaged in HWOL were viewed as more moral than those who engaged in Looking. There was also a main effect of Decision Option $(F(1,766)=11.83, p=.001)$ such that Communicators who expressed 
precommitment were viewed as more moral than those who did not precommit. All descriptive statistics for Study 3 are presented in Table 1.

Importantly, these results were qualified by a significant interaction of Decision Strategy and Decision Option $(F(1,766)=18.15, p<.001)$. In the No Precommitment condition, we replicated our previous findings: Communicators who engaged in HWOL were judged as more moral than those who engaged in Looking $(t(416)=6.71, p<.001)$. However, in the Precommitment condition, Communicators who engaged in HWOL were judged as equally moral as Communicators who expressed prosocial precommitment before Looking $(t(350)=$ $.060, p=.952)$. Figure 4 depicts these results.

Figure 4. Moral Judgment of the Communicator in Study 3.

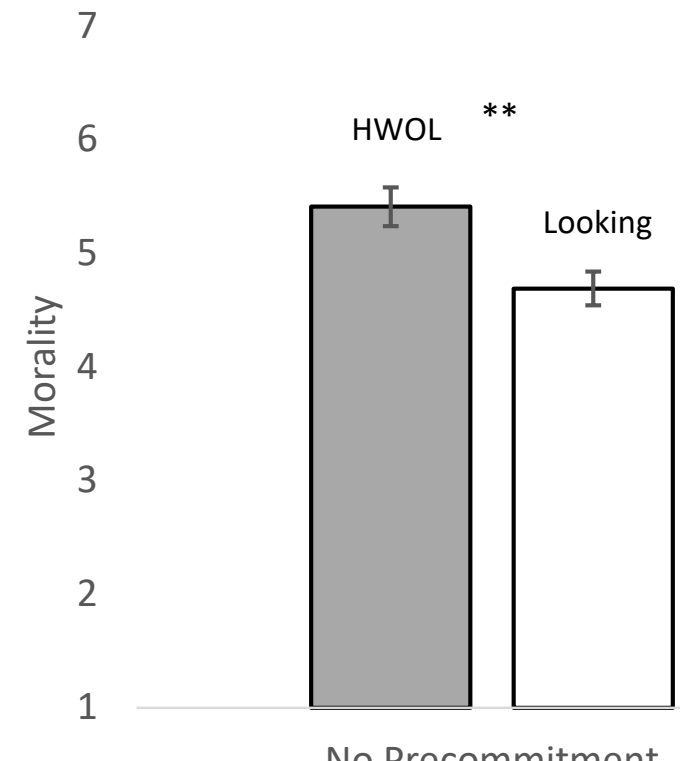

No Precommitment

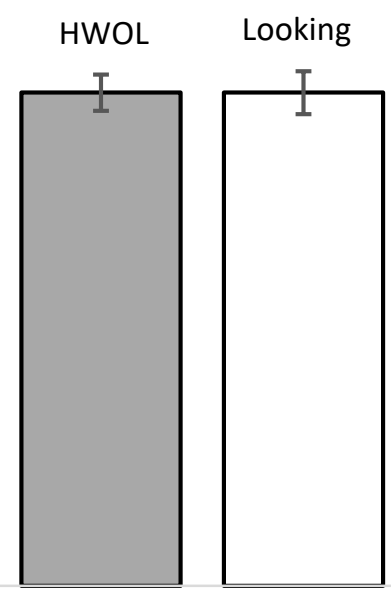

Precommitment

Notes. In Study 3, Communicators who engaged in HWOL were judged as more moral than those who engaged in Looking when they did not precommit. However, Communicators who engaged in HWOL were judged as equally moral as those who engaged in Looking when they expressed prosocial precommitment. Error bars represent $95 \%$ confidence intervals around the mean. ${ }^{* *}$ signifies $p<.001$. 
HONESTY AND MORAL ERROR AVOIDANCE 35

Table 1. Descriptive Statistics in Study 3.

\begin{tabular}{lcccc} 
& \multicolumn{2}{c}{ No Precommitment } & \multicolumn{2}{c}{ Precommitment } \\
\cline { 2 - 5 } Variable & HWOL & Look & HWOL & Look \\
\hline Morality & $5.41(1.17)$ & $4.69(1.03)$ & $5.34(1.12)$ & $5.34(1.35)$ \\
Tendency to tell Harmful Lies & $2.33(1.25)$ & $3.08(1.16)$ & $2.53(1.23)$ & $2.19(1.10)$ \\
Tendency to tell Helpful Lies & $3.14(1.41)$ & $4.32(1.22)$ & $3.30(1.51)$ & $5.38(1.45)$ \\
Slippery Slope of Deceptive Behavior & $2.16(1.34)$ & $3.00(1.43)$ & $2.04(1.17)$ & $2.79(1.67)$ \\
Internalized Moral Standards & $5.17(1.08)$ & $4.42(1.02)$ & $5.14(1.13)$ & $4.31(1.19)$ \\
\hline
\end{tabular}

Note. Standard deviations appear in parentheses.

\section{Exploratory Mechanisms.}

Tendency to tell Harmful Lies. Judgments of harmful lies mirrored moral character judgments. A two-way ANOVA on beliefs about the Communicator's tendency to tell harmful lies revealed a main effect of Decision Strategy $(F(1,766)=5.84, p=.016)$. Honesty without looking signaled that Communicators would be less likely to tell harmful lies compared to Communicators who Looked. This analysis also revealed a main effect of Decision Option $(F(1,766)=16.07, p<.001)$. Communicators who expressed precommitment were rated as less likely to tell harmful lies than those who did not precommit, consistent with the nature of the manipulation.

These effects were qualified by a significant interaction of Decision Strategy and Decision Option $(F(1,766)=38.63, p<.001)$. In the No Precommitment condition, Communicators who engaged in HWOL were judged as less likely to tell harmful lies than Communicators who Looked at the consequences $(t(416)=-6.29, p<.001)$. However, in the Precommitment condition, Communicators who engaged in HWOL were judged as more likely to tell harmful lies than those who Looked $(t(350)=2.62, p=.009)$.

Tendency to tell Helpful Lies. A two-way ANOVA on beliefs about the Communicator's tendency to tell helpful lies revealed a main effect of Decision Strategy $(F(1,766)=258.06, p<$ 
.001). Unconditionally honest Communicators were rated as less likely to tell helpful lies than Communicators who Looked. We also found a main effect of Decision Option $(F(1,766)=$ 35.66, $p<.001$ ) such that Communicators who expressed precommitment were rated more likely to tell helpful lies than those who did not precommit, consistent with the nature of the manipulation.

Notably, these effects were qualified by a significant interaction of Decision Strategy and Decision Option $(F(1,766)=19.77, p<.001)$. In the No Precommitment condition, Communicators who Looked were judged as more likely to tell helpful lies than Communicators who were HWOL $(t(416)=-9.12, p<.001)$. However, this effect was significantly larger in the Precommitment condition in which Communicators who Looked were rated as much more likely to tell helpful lies than HWOL Communicators $(t(350)=-13.07, p<.001)$.

Slippery Slope of Deceptive Behavior. A two-way ANOVA on beliefs that the Communicator's behavior would lead to slippery slope of deceptive behavior in the future revealed a main effect of Decision Strategy $(F(1,766)=59.72, p<.001)$. Communicators who were honest without looking were judged as less likely to be on a slippery slope of deceptive behavior in the future compared to those who Looked. We did not detect a main effect of Decision Option on these beliefs $(p=.107)$, nor a significant Decision Strategy x Decision Option interaction $(p=.697)$.

Internalized Moral Standards. A two-way ANOVA on judgments of the Communicator's internalized moral standards revealed a main effect of Decision Strategy $(F(1,766)=96.84, p<.001)$ such that unconditionally honest Communicators were judged as having greater internalized moral standards than those who Looked. There was no significant 
effect of Decision Option on this judgment $(p=.388)$, nor a significant Decision Strategy $\mathrm{x}$ Decision Option interaction $(p=.605)$.

Moderated Mediation Model. We conducted a moderated mediation model with 10,000 samples using Decision Strategy as the independent variable ( $1=$ HWOL, $0=$ Look), Decision Option as the moderator, and judgments of the Communicator's morality as the dependent variable (PRCOESS Macro for SPSS, Model 7, Hayes 2013). We conducted this analysis using tendency to tell harmful lies, tendency to tell helpful lies, beliefs about a slippery slope of deceptive behavior, and internalized moral standards as simultaneous mediators.

Results of the moderated mediation analysis are presented in Table 2 . We found significant moderated mediation through beliefs about the Communicator's tendency to tell harmful lies (index of moderated mediation $=-0.35, \mathrm{SE}=.07,95 \% \mathrm{CI}[-.50,-.23]$ ). When Communicators who Looked did not express precommitment, harmful lies mediated the effect of unconditional honesty on judgments of morality, such that engaging in HWOL lead to lower concerns about harmful lies, which led to higher judgments of morality (indirect effect $=.24$, SE $=.05,95 \%$ CI [.16, .34]). In contrast, when Communicators who Looked precommited to making a prosocial decision, harmful lies mediated the effect of unconditional honesty on judgments of morality in the opposite direction; engaging in HWOL lead to higher concerns about harmful lies, which led to lower ratings of morality (indirect effect $=-.11, \mathrm{SE}=.04,95 \%$ CI $[-.20,-.03])$.

We also found significant moderated mediation through beliefs about the Communicator's tendency to tell helpful lies (index of moderated mediation $=-0.10, \mathrm{SE}=.03$, 95\% CI [-.18, -.05]). When Communicators who Looked did not precommit, helpful lies mediated the effect of unconditional honesty on judgments of morality; HWOL lead to lower 
beliefs about the propensity to tell prosocial lies, which led to lower ratings of morality (indirect effect $=-.14, \mathrm{SE}=.03,95 \% \mathrm{CI}[-.20,-.08])$. However, the indirect effect of helpful lies was significantly larger when Communicators who Looked precommited to making a prosocial decision (indirect effect $=-.24, \mathrm{SE}=.05,95 \% \mathrm{CI}[-.35,-.14]$ ).

Although we also found evidence of mediation through internalized moral standards (consistent with Huppert et al., 2021), the strength of mediation did not depend on a Communicator's precommitment. These results suggest that concerns about overall moral standards may be independent of concerns of moral error avoidance. We find no evidence of mediation through slippery slope beliefs.

Table 2. Moderated Mediation Analyses from Study 3.

\begin{tabular}{lccc}
\hline Mediators & $\begin{array}{c}\text { No } \\
\text { Precommitment }\end{array}$ & Precommitment & $\begin{array}{c}\text { Index of } \\
\text { Moderated } \\
\text { Mediation }\end{array}$ \\
\hline Tendency to tell harmful lies & $\mathbf{0 . 1 6 , 0 . 3 4}$ & $-\mathbf{0 . 2 0 , - 0 . 0 3}$ & $\mathbf{- 0 . 5 0 , - 0 . 2 2}$ \\
Tendency to tell helpful lies & $-\mathbf{0 . 2 0 , - 0 . 0 8}$ & $-\mathbf{0 . 3 5 , - 0 . 1 4}$ & $-\mathbf{0 . 1 8 , - 0 . 0 5}$ \\
Slippery slope beliefs & $0.00,0.10$ & $0.00,0.09$ & $-.04, .02$ \\
Internalized moral standards & & & $-0.11,0.19$ \\
\hline
\end{tabular}

Note. Each set of numbers indicates the lower-level and upper-level 95\% confidence intervals around the indirect effect of the corresponding mediator. Using PROCESS Model 7 (Hayes, 2013), Decision Strategy was the IV, moral judgments was the DV, Decision Option was the moderator, and the items in the first column were simultaneous mediators. Bold typeface indicates significant effects (i.e., confidence intervals do not contain zero).

\section{Discussion}


In Study 3, we provide more direct evidence for an account of moral error avoidance using both mediation and moderation analyses. We manipulate whether "Looking" (unconditional rule-following) can lead to moral errors and find that the preference for unconditionally honesty is attenuated when Communicators who look for more information precommit to making prosocial decisions. These results are consistent with the moral error avoidance account: when conditional rule-following also minimizes moral error (i.e., ensuring that harmful lies will not be told), unconditional rule-following is no longer seen as a superior moral strategy.

We also measured participants’ underlying judgments. Our mediation results suggest that conditional honesty is troubling not simply because it could lead to the more costly moral error (harmful lies) in the present context, but also because it signals that a person may be likely to commit those moral errors in the future. Communicators who looked for information were judged as more likely to tell harmful lies (across contexts) compared to Communicators who were unconditionally honest, which led them to be seen as less ethical. This inference, however, was attenuated when Communicators precommitted to making prosocial communication decisions.

Our mediation results also suggest that beliefs about the Communicator's general moral standards cannot fully explain our results. Although judgments of the Communicator's moral standards (i.e., the degree to which they feel guilty about lying and genuinely value honesty) did mediate the relationship between unconditional honesty and moral judgments, this was the case regardless of whether precommitment was possible. These results suggest that beliefs about a person’s moral commitment (e.g., Critcher et al., 2013; Evans \& Van de Calseyde, 2017; Jordan 
et al., 2016) and concerns about moral error may be two distinct, and separable mechanisms underlying the preference for absolute moral rules.

\section{Study 4 Judgments of Unconditional Honesty and Unconditional Prosociality}

Study 4 extends our investigation in two ways. First, we provide a second test of the prediction that the preference for HWOL is attenuated when it is certain that Looking does not

lead to a moral error (as in Study 3). We test this by examining perceptions of HWOL and Looking once the outcomes of those decision strategies are known.

We also examine whether the preference for unconditional moral rule-following is unique to honesty. We manipulate whether Communicators start with information about what is honest (and have to decide whether to find out whether their honesty would help or harm others before making a communication decision) or with information about what is helpful (and have to decide whether helping others entails lying or truth-telling before making a helping decision). In doing so, we test whether people have equivalent preferences for unconditional honesty (i.e., HWOL) and unconditional prosociality (i.e., PWOL or prosociality without looking).

\section{Method}

Participants. As preregistered (https://aspredicted.org/blind.php?x=9sq63e), we aimed to recruit 800 participants from Amazon Mechanical Turk (MTurk). We ended up with a final sample of 799 participants (mean age $=37.44 ; 53 \%$ female).

Procedure and materials. Participants learned about a Communicator who had previously participated in a study in which they played "the Number Game," which was similar to the Coin Flip Game used in Studies 1 and 3. In this game, Communicators were asked to report whether a number generated by a random number generator was odd or even. We manipulated whether the Communicator first learned the true outcome of the random number 
generator, without knowing how their report of the number would affect their partner (we label this "Honesty Context," which is conceptually identical to the context we examined in Studies 13), or alternatively, whether the Communicator first learned how their report of the number would affect their partner, without knowing the true outcome of the random number generator (we label this "Prosociality Context”). We also informed participants of the ultimate choice the Communicator made in each context, including whether it was honest or deceptive, and whether it helped or harmed the Target. That is, participants in this study were randomly assigned to a condition from a 2 (Context: Honesty vs. Prosociality) x 2 (Decision Strategy: Not Look vs. Look) x 2 (Honesty Outcome: Truth vs. Lie) x 2 (Prosocial Outcome: Help vs. Harm) betweensubjects design.

In the Number Game, Communicators had to report whether the number generated by a random number generator was odd or even. The Communicator's report was associated with monetary consequences for a partner, called the Target. In the Honesty Context, the Communicator knew the true outcome of the number generator but did not know how much money their partner would earn if they reported that the number was odd (versus even). In the Prosociality Context, the Communicator knew the monetary values associated with reporting odd versus even, but did not know the true outcome of the number generator. Therefore, Communicators in this context could choose to report something that was ultimately prosocial (or antisocial), without knowing whether their report was true or false.

Participants first learned about the Number Game. Then, participants learned the Communicator's decision strategy. In the Not-Look conditions, the Communicator chose to initially report a number without full information (either about how the report would affect the Target or about the truth value of the report). Notably, in the Honesty Context/Truth Outcome 
Condition, Not-Looking is identical to our operationalization of HWOL in prior studies. After learning of the Communicator's decision strategy, participants learned the consequences of this decision (i.e., whether Not-Looking ultimately led to a helpful or harmful honest or dishonest decision).

In the Look conditions, the Communicator chose to look and learn about the unknown information before reporting a number. In the Honesty Context, Communicators who looked found the monetary values associated with reporting odd versus even and therefore whether truth telling would help or harm the Target. Then, the Communicator either helped or harmed the Target, via truth telling or lying by reporting odd or even. In the Prosociality Context, Communicators who looked found out whether the number generated was actually odd or even, and therefore whether the message that helped the Target was honest or deceptive. Then the Communicator either helped or harmed the Target, via truth telling or lying by reporting odd or even.

Lastly, participants saw a summary of the decision the Communicator made. They were reminded of the Communicator's known and unknown information, saw the Communicator's decision strategy (i.e., Not Look vs. Look), the Honesty Outcome (whether the Communicator ultimately told the truth or lied), and the Prosocial Outcome (whether the Communicator ultimately helped or harmed another person).

The main dependent variable was moral judgment of the Communicator; we used the same three-item composite as Studies 1 and $3(\alpha=.971) .{ }^{4}$

\footnotetext{
${ }^{4}$ We also included measures of perceived trustworthiness, perceived benevolence, perceived integrity, and perceived honesty. The details of all ancillary measures in our studies are reported in the SOM.
} 
Figure 5. Moral Judgment in the Honesty and Prosociality Contexts
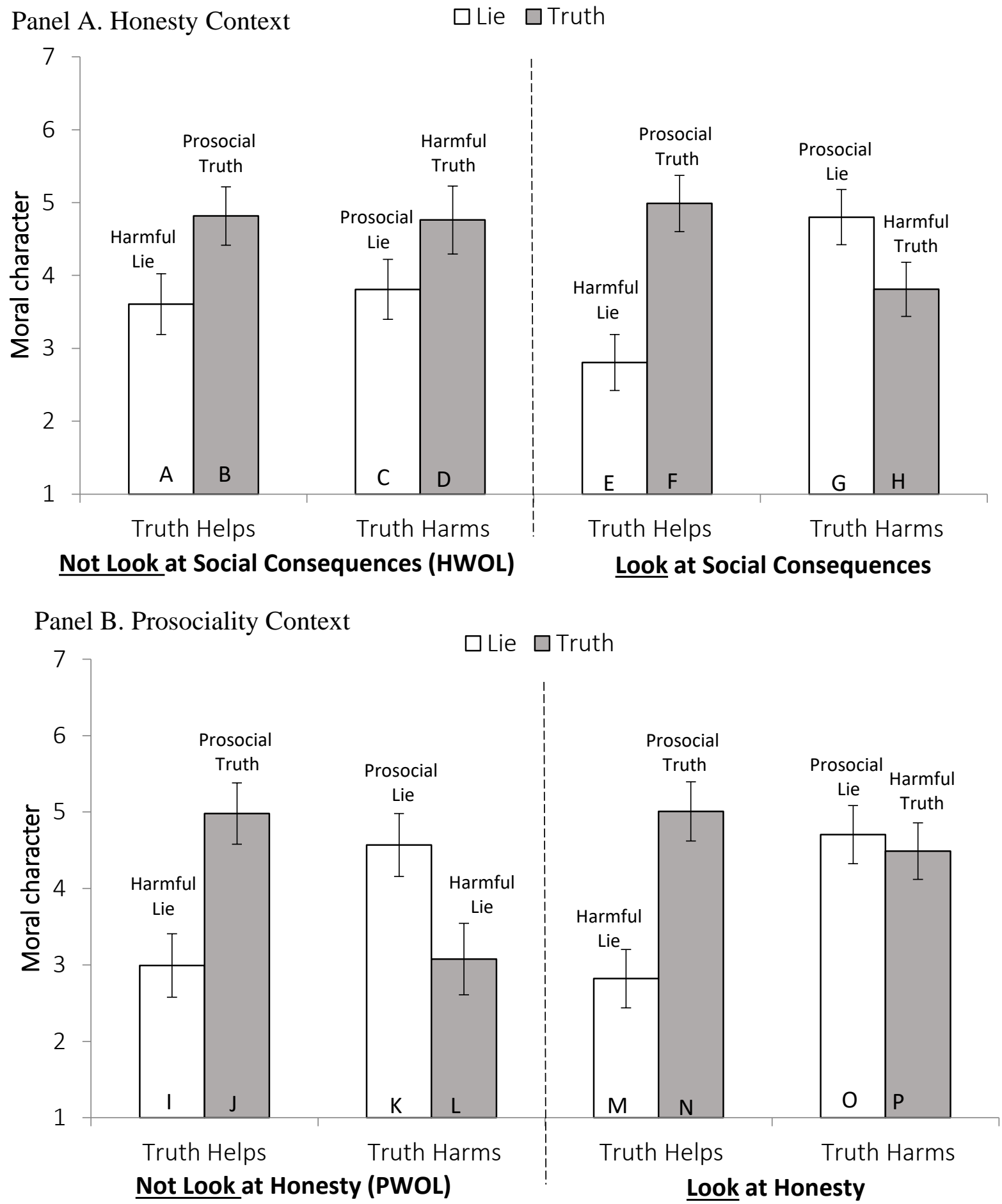

Note. Study 4 results. Error bars represent 95\% confidence intervals around the mean. 
HONESTY AND MORAL ERROR AVOIDANCE 44

\section{Results}

We report the full results of 2x2x2x2 ANOVAs (our preregistered analysis) on all dependent variables in SOM 1.4, along with an abbreviated discussion of significant main effects and interactions. However, here, we focus on the contrasts that test our theoretical questions of interest regarding judgments of moral character, which we outline below. ${ }^{5}$

\section{Is HWOL seen as a more moral decision strategy than Looking, holding outcomes}

constant? To examine this question, we compare moral judgments of HWOL (cells B and D in Figure 5, Panel A) to Looking, holding outcomes constant (cells F and H in Figure 5, Panel A). Specifically, we examine the effect of Decision Strategy (Not Look vs. Look) and Prosocial Outcome (Helping vs. Harmful) among Communicators who told the truth (Honesty Outcome: Truth) in the Honesty Context conditions.

Similar to Study 1, we find a main effect of Decision Strategy $(F(1,197)=5.62, p=$ $.019)$, such that HWOL $(M=4.79, S D=.96)$ is seen as more moral than Looking $(M=4.40, S D$ $=1.43)$. We also find a main effect of Prosocial Outcome $(F(1,197)=14.07, p<.001)$, such that Prosociality $(M=4.91, S D=.96)$ is seen as more moral than Harming $(M=4.25, S D=1.41)$.

Importantly, these main effects were qualified by a significant Decision Strategy $\mathrm{x}$ Prosocial Outcome interaction $(F(1,197)=11.65, p=.001)$. HWOL $(M=4.76, S D=1.04)$ was seen as more ethical than Looking $(M=3.81, S D=1.55)$ when these decision strategies led to Harm $(t(97)=-3.52, p=.001)$, but HWOL $(M=4.82, S D=.88)$ was seen similarly as Looking $(M=4.99, S D=1.03)$ when these decisions led to Help $(t(100)=-.899, p=.371)$. The

\footnotetext{
${ }^{5}$ We converged on these analyses as we developed our theory, which occurred after we preregistered and ran this study. For robustness, we ran a preregistered replication of the HWOL condition, including our focal analyses (see Study S7 of the SOM; and Table 3 for focal descriptive statistics). We generally find the same pattern of results, though some vary in significance.
} 
interaction also reveals that although there was no difference between Help and Harm when the Communicator did Not Look $(t(93)=-.280, p=.780)$, Help was seen as significantly more moral than Harm when it followed Looking $(t(104)=-.461, p<.001)$. In other words, Communicators were penalized more for knowingly causing harm than for remaining intentionally ignorant of foreseeable, and realized, harm (Cushman et al., 2006; Foot, 1967; Royzman \& Baron, 2002).

\section{Is HWOL seen as a more moral decision strategy than Looking, when Looking} results in prosocial outcomes? We also compare moral judgments of HWOL (cells B and D in Figure 5, Panel A) to Looking when it results in prosociality (cells F and G in Figure 5, Panel A). In other words, we compare the strategy of unconditional honesty to the strategy of looking in order to promote social good.

To do this, we conduct a simple t-test to compare the moral judgment of HWOL

(Context: HWOL, Decision Strategy: Not Look, Honesty Outcome: Truth) to the moral judgment of Prosocial Looking (Context: HWOL, Decision Strategy: Look, Prosocial Outcome: Help). There was no difference between Not Look $(M=4.79, S D=.95)$ and Looking $(M=4.90, S D=$ 1.13) when Looking resulted in prosocial outcomes $(t(196)=.716, p=.475)$. Together, these two analyses corroborate the result of Study 3: People judge HWOL (vs. Looking) as a more ethical decision strategy unless it is certain that looking at the consequences yields a prosocial outcome.

\section{In the Prosociality Context, is Not Looking seen as a more moral decision strategy} than Looking, holding outcomes constant? Next, we examine whether people also exhibit a preference for unconditional moral rule-following in the context of prosociality. That is, when people start off with information about what benefits a partner, are they rewarded for making statements that promote social welfare, without knowing whether those statements are truthful? We conduct a similar analysis to the first analysis we conducted in the Honesty Context: We 
compare moral judgments of prosociality without looking (Not look at Honesty) (cells J and K in Figure 5, Panel B) to Looking (cells N and O in Figure 5, Panel B), holding outcomes constant. In other words, we compare judgments of prosocial statements, when the truthfulness of those statements are, or are not yet, known.

To do this, we examine the effect of Decision Strategy (Not Look vs. Look) and Honesty Outcome (Truth vs. Lie) among communicators who helped others (Prosocial Outcome: Help) in the Prosociality Context. There was a significant main effect of Honesty Outcome $(F(1,195)=$ 4.256, $p=.040)$, such that communicators who ultimately ended up telling the truth $(M=4.99$, $S D=1.21)$ were seen as more moral than those who lied $(M=4.64, S D=1.22)$. Unlike the Honesty Context, however, we found no significant main effect of Decision Strategy $(F(1,195)=$ $.229, p=.633$ ), nor did we find a significant Decision Strategy $\mathrm{x}$ Honesty Outcome interaction $(F(1,195)=.099, p=.753)$.

In other words, there does not seem to be a preference for unconditional prosociality. Although people give moral credit to communicators who are honest without looking at the social consequences of their honesty, they do not give moral credit to communicators who are prosocial without looking at the honesty of their statements. We replicate these effects in Study S5 (see SOM 2.5).

\section{Discussion}

Study 4 extends our investigation in several ways. First, it replicates the results of Study 3: Unconditional honesty is not seen as more ethical than Looking if it is certain that Looking leads to prosocial decisions. This finding is consistent with the moral error avoidance account; once people know that conditional honesty does not lead to the gravest moral error, they do not penalize it. 
Study 4, however, offers new insights into the nature of these effects. Examining the full pattern of results in the Honesty context sheds light on how honest and deceptive behaviors are judged as a function of the information available at the moment of decision-making. In the Looking condition of the Honesty context, there is a significant Honesty Outcome $\mathrm{x}$ Prosocial Outcome interaction $(F(1,207)=4.572, p=.034)$. Prosocial truth-telling (Column F in Figure 5 Panel A) is seen as significantly more ethical than harmful lying (Column E in Figure 5 Panel A, $t(106)=8.25, p<.001$ ), and prosocial lying (Column G in Figure 5 Panel A) is seen as more ethical than harmful truth-telling (Column H in Figure 5 Panel A, $t(101)=3.57, p=.001$ ). In other words, consistent with Studies 2a and 2b and prior work, the moral judgment of deception depends on its social consequences, if decision makers know these consequences at the time of making the decision. Furthermore, consistent with an error avoidance account, these judgments are asymmetric such that harmful lying (relative to prosocial truth-telling; $d=1.59$ ) is a more significant error than harmful truth-telling (relative to prosocial lying; $d=-.704$ ).

However, in the Not-Looking condition, there is not a significant Lie x Outcome interaction $(p=.660)$. There is just main effect of Honesty $(F(1,190)=41.68, p<.001)$. If one simply follows the moral rule of honesty, it does not matter if that rule leads to (foreseeable) harm. Whereas Studies 1-3 demonstrate that unconditional honesty is rewarded a priori (before harm is realized), Study 4 finds that it is also rewarded post hoc, after it causes harm. This finding suggests, consistent with Study $2 \mathrm{~b}$, that preferences for unconditional honesty are not driven by a failure to anticipate the harm it may cause. Intentional ignorance of honesty's consequences seems to be rewarded. We replicate these patterns of results in Study S7 (see SOM 2, and Table 3); albeit some comparisons vary in significance. 
Study 4 also provides initial insight into the generalizability of preferences for unconditional morality. Interestingly, we do not find that people have a preference for unconditional prosociality relative to Looking. We find this both when the outcomes of these strategies are held constant (present study) and before the consequences of these strategies are known (see Study S5 in SOM 2). Nonetheless, it is important to note that unconditional prosociality is no worse than Looking. This suggests that unconditional moral rule-following may still be valued as a general strategy to be applied across contexts. We return to the discussion of moral error avoidance across domains in the General Discussion. ${ }^{6}$

\section{General Discussion}

Across four main studies (and ten supplemental studies), we propose and test a theory of moral error avoidance in the context of honesty. We argue that moral error avoidance can explain why people reward unconditional honesty, despite also believing that prosocial lying is more

\footnotetext{
${ }^{6}$ It is worth noting that the full pattern of results is actually quite similar across contexts. As in the Honesty context, there is not a significant Honesty Outcome x Prosociality Outcome interaction $(p=.404)$ in the Not-Looking condition of the Prosociality context; There is just a main effect of Prosociality $(p<.001)$. Furthermore, as in the Honesty context, there is a significant Honesty Outcome $x$ Prosociality Outcome interaction in the Looking condition $(p=$ .001). Following Looking, prosocial truth-telling (Column $\mathrm{N}$ in Figure 5 Panel B) is seen as significantly more ethical than harmful lying (Column $\mathrm{M}$ in Figure 5 Panel $\mathrm{B}, p<.001$ ), but prosocial lying (Column $\mathrm{G}$ in Figure 5 Panel B) is seen as directionally but not significantly more ethical than harmful truth-telling (Column H in Figure 5 Panel B, $p=.411$ ). These results suggest that in both contexts, blind moral rule-following is not penalized when it leads to foreseeable transgressions in either context and that people make asymmetric judgments of the errors associated with lying and truth-telling.

What seems to drive the lack of penalty towards Looking in the Prosociality context is the positive judgment of prosocial lying after the Communicator looks. Though harmful truthtelling is penalized in the Honesty context when it follows Looking (Column $\mathrm{H}$ in Figure 5 Panel A) versus Not-Looking (Column D in Figure 5 Panel A; $p<.001$ ); prosocial lying is not penalized in the Prosociality context when it follows Looking (Column O in Figure 5 Panel B) versus Not-Looking (Column K in Figure 5 Panel B; $p=.564$ ). In other words, not using information that you sought out about whether an action causes harm is penalized, but not using information about whether an action is deceptive is not penalized. It is possible that this reflects the strength of people's endorsement of prosocial lies.
} 
ethical than harmful truth-telling. In Study 1, we find that communicators who engage in unconditional honesty are judged to be more moral, and are more trusted as advisors, than communicators who look at the social consequences of honesty before deciding whether to tell the truth or lie. In other words, unconditional honesty is rewarded, despite reflecting strategic ignorance of social welfare.

In Studies 2a and 2b, we unpack these findings further to understand how people judge honesty when the social welfare consequences of honesty are known versus unknown. We crafted face-valid scenarios in which the perceived errors associated with lying and truth-telling were asymmetric. In these scenarios, as in many real-world situations, prosocial lying was seen as more ethical than harmful truth telling, but the perceived moral cost of telling harmful truths (rather than prosocial lies) was smaller than the costs of telling harmful lies (rather than prosocial truths). In these studies, we find that people believe that communicators are obligated to condition their communication decisions on the social consequences of honesty (and tell prosocial lies rather than harmful truths) when the social consequences of honesty are known. However, people also believe that communicators should avoid finding out this information if they do not have it in the first place, thereby upholding a policy of absolute honesty. These results are consistent with the theory of moral error avoidance. When information about the consequences of honesty is unknown, looking for that information could lead to the most prosocial outcome (either a prosocial lie or prosocial truth), but it also could lead to the more costly error of telling a harmful lie. Following a rule of unconditional honesty minimizes error by ensuring that communicators cannot tell a harmful lie. Thus, the preference for unconditional honesty when the consequences of honesty are unknown suggests that people care more about 
HONESTY AND MORAL ERROR AVOIDANCE 50

avoiding moral error than they care about maximizing the goodness of each communication decision.

In Study 3, we directly test whether unconditional honesty is rewarded because it eliminates the possibility of harmful lies (the more costly moral error). We find that it is; when it is certain that looking for more information will not lead to harmful lies, unconditional honesty is no longer rewarded. We find the same pattern of results in Study 4 in which we also explore judgments of unconditional prosociality. People believe it is more ethical to simply tell the truth than to look for information about the social consequences of one's words, but people do not think it is more ethical to simply say what helps others rather than verifying the honesty of their words. In other words, the rewards of unconditional rule-following seem to be somewhat unique to honesty.

\section{Meta-analytic results}

In a number of supplementary studies, we provide further evidence for these results and rule out alternative explanations. We report these studies - which reflect our entire file drawer of pre-registered studies that included moral judgments of HWOL and Looking - in our supplementary online materials. Here, we provide a meta-analysis of these studies, and a brief discussion of key findings. We encourage interested readers to examine our supplement for further details.

Our meta-analysis ultimately included 11 studies (Studies 1, 3 and 4 from the main manuscript, and Studies S1, S2, S3, S4, S5, S6, S7, and S8 reported in the online supplement). In each study, we included only the conditions that examined judgments as HWOL (omitting conditions that examined Lying without Looking, or Prosociality without Looking; see Table 3 notes for details). We used the meta-analysis package of SPSS 28, using random-effects 
modeling and inverse variance weights to assign weights to studies based on their sample size (Lipsey \& Wilson, 2001). The summary statistics from each condition of each study are provided in Table 3. Though they were not included in the meta-analysis due to differences in study designs and dependent variables, we also provide a summary of all studies that examined the choice of HWOL, Looking, or LWOL within a scenario paradigm, in Table 4.

Overall, we find consistent evidence that HWOL is judged to be more ethical than Looking; meta-analytic $d=.374,95 \%$ CI [.241, .507]. Though the meta-analytic effect size is relatively small, we note that our meta-analysis includes conditions in which we expected (and did find) an attenuation of our effects (e.g., in Studies 4 and S7, when HWOL and Looking both led to prosocial outcomes, and in Study 3 when the communicators precommitted to prosociality). Therefore, this analysis suggests that in general, HWOL is likely to be seen as more moral than Looking. However, for completeness, we also conducted a sub-group analysis to examine the overall effect of HWOL versus Looking when Looking did, versus did not, yield prosocial outcomes. When Looking did not yield prosocial outcomes, we continue to see a robust moral preference for HWOL; meta-analytic $d=.460,95 \%$ CI [.347, .573]. However, when Looking did yield prosocial outcomes - that is, when Looking could not lead to moral error HWOL was not seen as more moral than Looking; meta-analytic $d=-.115$, 95\% CI [-.295, .064]. These results are consistent with Studies 3 and 4 of the main manuscript, as well as the broader theory of moral error avoidance. 
HONESTY AND MORAL ERROR AVOIDANCE 52

Table 3. Meta-analysis of all studies that examine moral judgments of HWOL and Looking

\begin{tabular}{|c|c|c|c|c|c|c|c|c|c|c|c|}
\hline \multirow[b]{2}{*}{ Study } & \multirow[b]{2}{*}{ Main finding } & \multirow[b]{2}{*}{ Additional factors } & \multicolumn{2}{|c|}{ HWOL } & \multicolumn{3}{|c|}{ Looking } & \multirow[b]{2}{*}{$n$} & \multirow[b]{2}{*}{$d$} & \multicolumn{2}{|c|}{$95 \% \mathrm{Cl}$} \\
\hline & & & $M$ & $S D$ & $n$ & $M$ & $S D$ & & & Lower & Upper \\
\hline 1 & $\begin{array}{l}\text { HWOL is seen as more moral } \\
\text { than Looking }\end{array}$ & $N / A^{a}$ & 4.37 & 1.14 & 114 & 4.06 & 1.15 & 126 & 0.273 & 0.019 & 0.528 \\
\hline \multirow{3}{*}{3} & \multirow{3}{*}{$\begin{array}{l}\text { HWOL is seen as more moral } \\
\text { than Looking, unless Looking is } \\
\text { paired with a precommitment to } \\
\text { prosocial decisions }\end{array}$} & No precommitment ${ }^{\mathrm{a}}$ & 5.41 & 1.17 & 168 & 4.69 & 1.03 & 250 & 0.669 & 0.468 & 0.869 \\
\hline & & Precommitment $^{\mathrm{b}}$ & 5.34 & 1.12 & 154 & 5.34 & 1.35 & 198 & 0.007 & -0.204 & 0.217 \\
\hline & & Overall & 5.38 & 1.14 & 366 & 4.93 & 1.20 & 404 & 0.377 & 0.234 & 0.520 \\
\hline \multirow{3}{*}{$4^{*}$} & \multirow{3}{*}{$\begin{array}{l}\text { HWOL is seen as more moral } \\
\text { than Looking when the } \\
\text { strategies lead to social harm, } \\
\text { but not when the strategies lead } \\
\text { to prosocial outcomes }\end{array}$} & Prosocial outcome: Help ${ }^{b}$ & 4.82 & 0.88 & 49 & 4.99 & 1.03 & 53 & -0.178 & -0.567 & 0.211 \\
\hline & & Prosocial outcome: Harm ${ }^{\mathrm{a}}$ & 4.76 & 1.04 & 46 & 3.81 & 1.55 & 53 & -0.710 & -1.115 & -0.301 \\
\hline & & Overall & 4.79 & 0.96 & 95 & 4.40 & 1.43 & 106 & 0.316 & 0.037 & 0.595 \\
\hline \multirow[b]{3}{*}{$\mathrm{S} 1$} & \multirow{3}{*}{$\begin{array}{l}\text { HWOL is seen as more moral } \\
\text { than Looking, regardless of } \\
\text { whether these decision } \\
\text { strategies influence payoffs for } \\
\text { the self or others }\end{array}$} & Personal consequences & 5.32 & 1.13 & 221 & 4.22 & 1.25 & 216 & 0.924 & 0.727 & 1.121 \\
\hline & & Social consequences & 5.27 & 1.11 & 187 & 4.35 & 1.10 & 193 & 0.834 & 0.624 & 1.043 \\
\hline & & Overall ${ }^{\mathrm{a}}$ & 5.29 & 1.12 & 408 & 4.28 & 1.18 & 409 & 0.883 & 0.739 & 1.026 \\
\hline \multirow[t]{4}{*}{$\mathrm{S} 2$} & \multirow{4}{*}{$\begin{array}{l}\text { HWOL is seen as more moral } \\
\text { than Looking, regardless of } \\
\text { whether these decision } \\
\text { strategies influence payoffs for } \\
\text { the self or others }\end{array}$} & Personal consequences & 4.51 & 1.05 & 101 & 3.93 & 1.56 & 104 & 0.437 & 0.159 & 0.713 \\
\hline & & Social consequences & 4.13 & 1.15 & 99 & 3.94 & 1.35 & 101 & 0.149 & -0.129 & 0.426 \\
\hline & & Personal \& social cons. & 4.38 & 1.31 & 97 & 4.01 & 1.92 & 107 & 0.224 & -0.052 & 0.499 \\
\hline & & Overall $^{\mathrm{a}}$ & 4.34 & 1.18 & 297 & 3.96 & 1.63 & 312 & 0.266 & 0.107 & 0.426 \\
\hline \multirow[t]{3}{*}{ S3 } & \multirow{3}{*}{$\begin{array}{l}\text { HWOL is seen as more moral } \\
\text { than Looking, regardless of } \\
\text { whether harm is salient }\end{array}$} & Harm not salient & 4.63 & 1.12 & 192 & 4.28 & 1.23 & 202 & 0.301 & 0.102 & 0.499 \\
\hline & & Harm salient & 4.73 & 1.03 & 199 & 4.42 & 1.11 & 207 & 0.292 & 0.096 & 0.488 \\
\hline & & Overall $^{\mathrm{a}}$ & 4.68 & 1.07 & 391 & 4.35 & 1.17 & 409 & 0.297 & 1.570 & 0.436 \\
\hline
\end{tabular}


HONESTY AND MORAL ERROR AVOIDANCE 53

\begin{tabular}{|c|c|c|c|c|c|c|c|c|c|c|c|}
\hline \multirow[t]{4}{*}{ S4 } & \multirow{4}{*}{$\begin{array}{l}\text { HWOL is seen as more moral } \\
\text { than Looking when these } \\
\text { strategies influence payoffs for } \\
\text { others, regardless of whether a } \\
\text { communicator also engages in } \\
\text { HWOL or Looking when these } \\
\text { strategies influence payoffs for } \\
\text { the self }\end{array}$} & HWOL, personal cons. & 5.45 & 1.07 & 86 & 4.74 & 1.25 & 89 & 0.612 & 0.308 & 0.914 \\
\hline & & Looking, personal cons. & 4.65 & 1.17 & 91 & 4.40 & 1.24 & 94 & 0.208 & -0.081 & 0.497 \\
\hline & & No information & 5.12 & 1.07 & 85 & 4.68 & 1.11 & 94 & 0.398 & 0.102 & 0.694 \\
\hline & & Overall ${ }^{\mathrm{a}}$ & 5.06 & 1.15 & 262 & 4.60 & 1.20 & 277 & 0.390 & 0.220 & 0.561 \\
\hline $\mathrm{S} 5 *$ & $\begin{array}{l}\text { HWOL is seen as more moral } \\
\text { than Looking }\end{array}$ & $N / A^{a}$ & 4.80 & 1.06 & 199 & 4.19 & 1.27 & 200 & 0.524 & 0.324 & 0.724 \\
\hline S6 & $\begin{array}{l}\text { HWOL is seen as more moral } \\
\text { than Looking }\end{array}$ & $N / A^{a}$ & 4.96 & 1.05 & 207 & 4.67 & 1.27 & 211 & 0.250 & 0.057 & 0.442 \\
\hline \multirow[t]{3}{*}{ S7* } & \multirow{3}{*}{$\begin{array}{l}\text { HWOL is seen as more moral } \\
\text { than Looking when the } \\
\text { strategies lead to social harm, } \\
\text { but not when the strategies lead } \\
\text { to prosocial outcomes }\end{array}$} & Prosocial outcome: Help ${ }^{b}$ & 5.24 & 1.30 & 101 & 5.56 & 1.28 & 97 & -0.247 & -0.527 & 0.033 \\
\hline & & Prosocial outcome: Harm ${ }^{\mathrm{a}}$ & 4.78 & 1.61 & 101 & 4.06 & 1.98 & 100 & 0.398 & 0.118 & 0.677 \\
\hline & & Overall & 5.01 & 1.48 & 202 & 4.80 & 1.83 & 197 & 0.127 & -0.069 & 0.324 \\
\hline \multirow[t]{6}{*}{ S8* } & \multirow{3}{*}{$\begin{array}{l}\text { HWOL is seen as more moral } \\
\text { than Looking, regardless of } \\
\text { whether Looking is paired with } \\
\text { prosocial intentions }\end{array}$} & No intentions expressed & 5.47 & 1.06 & 196 & 4.89 & 0.99 & 206 & 0.565 & 0.366 & 0.764 \\
\hline & & Prosocial intentions & na & na & $n a$ & 4.86 & 0.94 & 199 & 0.610 & 0.408 & 0.812 \\
\hline & & Overall $^{\mathrm{a}}$ & 5.47 & 1.06 & 196 & 4.88 & 0.97 & 405 & 0.597 & 0.423 & 0.770 \\
\hline & \multicolumn{8}{|c|}{ Overall meta-analytic estimate: } & 0.374 & 0.241 & 0.507 \\
\hline & \multicolumn{8}{|c|}{ Meta-analytic estimate when Looking did not lead to prosocial outcomes ${ }^{a}$ : } & 0.460 & 0.347 & 0.573 \\
\hline & \multicolumn{8}{|c|}{ Meta-analytic estimate when Looking did lead to prosocial outcomes ${ }^{b}$ : } & -.113 & -.291 & 0.066 \\
\hline
\end{tabular}

Note. *indicates that the study also included additional cells (manipulations) that did not explore judgments of HWOL. In Study 4, we only report results from the Honesty Outcome: Truth and Context: Honesty conditions. Study 4 also explored judgments of Lying (Honesty Outcome: Lie) and Prosociality without looking (Context: Prosociality). In Study S5, we only report results from the Context: Honesty conditions. Study 5 also explored judgments of Prosociality without looking (Context: Prosociality). In Study S7, we only report results from the Honesty Outcome: Truth conditions. Study 4 also explored judgments of Lying (Honesty Outcome: Lie). Full results, including all manipulations, are available in the SOM. In Study S8, we include all conditions, but compare HWOL to Looking both with and without intentions expressed. "indicates that the condition was included in the "Looking did not lead to prosocial outcomes" subgroup analysis. bindicates that the condition was included in the "Looking did lead to prosocial outcomes" subgroup analysis. 
HONESTY AND MORAL ERROR AVOIDANCE 54

Table 4. Summary of all studies that examine the choice of HWOL, LWOL and Looking as the most ethical decision

\begin{tabular}{|c|c|c|c|c|c|c|c|c|c|c|c|}
\hline \multirow[b]{2}{*}{ Study } & \multirow[b]{2}{*}{ Main finding } & \multirow[b]{2}{*}{$\begin{array}{l}\text { Additional } \\
\text { factors }\end{array}$} & \multicolumn{3}{|c|}{ Outcomes known } & \multicolumn{3}{|c|}{ Outcomes unknown } & \multirow[b]{2}{*}{$p$} & \multirow{2}{*}{\multicolumn{2}{|c|}{$n$}} \\
\hline & & & HWOL & LWOL & Looking & HWOL & LWOL & Looking & & & \\
\hline $2 a$ & $\begin{array}{l}\text { HWOL is preferred more when } \\
\text { consequences are unknown versus } \\
\text { known }\end{array}$ & N/A & $40.00 \%$ & $16.00 \%$ & $44.00 \%$ & $58.00 \%$ & $13.00 \%$ & $29.00 \%$ & & 0.035 & 200 \\
\hline \multirow[t]{2}{*}{$2 b$} & $\begin{array}{l}\text { HWOL is preferred more when } \\
\text { consequences are unknown versus }\end{array}$ & $\begin{array}{l}\text { Known-followed } \\
\text { by-Unknown }\end{array}$ & $47.40 \%$ & $12.10 \%$ & $40.50 \%$ & $64.10 \%$ & $17.10 \%$ & $18.80 \%$ & & $<.001^{\wedge}$ & 116 \\
\hline & known & Unknown only & & & N/A & $68.00 \%$ & $20.00 \%$ & $12.00 \%$ & & $0.375^{\#}$ & 100 \\
\hline \multirow[t]{2}{*}{ S9 } & $\begin{array}{l}\text { When honesty can cause high harm, } \\
\text { it is more likely that HWOL is }\end{array}$ & Moderate Harm & & & $54.00 \%$ & $35.10 \%$ & $4.64 \%$ & $60.26 \%$ & & 0.468 & 301 \\
\hline & $\begin{array}{l}\text { preferred more when consequences } \\
\text { are unknown versus known. The } \\
\text { preference for LWOL increases when } \\
\text { honesty causes greater harm. }\end{array}$ & High Harm & $19.33 \%$ & $7.33 \%$ & $73.33 \%$ & $28.48 \%$ & $11.26 \%$ & $60.26 \%$ & & 0.050 & 301 \\
\hline \multirow{2}{*}{ S10 } & The preference for LWOL increases & Moderate Harm & & & N/A & $26.50 \%$ & $21.30 \%$ & $52.20 \%$ & & $.103^{+}$ & 249 \\
\hline & & High Harm & & & N/A & $26.60 \%$ & $29.00 \%$ & $44.40 \%$ & & N/A & 248 \\
\hline
\end{tabular}

Note. ${ }^{\wedge}$ indicates that within this condition of Study 2b, the p-value corresponds to a Wilcoxon Signed Ranks test which compares the distributions of choices when the outcomes are Known versus Unknown (within subjects). \#indicates that within this condition of Study $2 \mathrm{~b}$, the $\mathrm{p}$-value corresponds to a $\chi 2$ test which compares the distributions of choices when the outcomes are Known (from the Known-followed-by-Unknown condition) versus Unknown (Unknown only condition, between subjects). ${ }^{+}$indicates that in Study S10, the p-value corresponds to a $\chi 2$ test which compares the distribution of choices under High versus Moderate harm. In Studies 2a and s9, the p-value corresponds to a $\chi 2$ test that compares the distribution of choices when outcomes are Known versus Unknown 
These studies also provide evidence that is inconsistent with several alternative theories. One alternative explanation for our effects is that observers care primarily about the intentions of a communicator. Unconditional honesty clearly signals honest intentions, but the intentions associated with Looking are more ambiguous; a communicator could look for more information because they desire to help a target, harm a target, or are simply curious. In Study S8, we explored this possibility by manipulating whether the communicator expressed prosocial intentions when they chose to Look. We found that communicators’ prosocial intentions were not sufficient to attenuate the preference for unconditional honesty. These results suggest that people care more about the potential consequences of Looking than the intentions behind it. A communicator could have good intentions, but then end up telling a harmful lie after looking, due to either temptation or carelessness. Our findings suggest that the possibility of telling a harmful lie must be completely eliminated in order for a communication strategy to be deemed moral. As a result, we observe a preference for unconditional honesty in all cases except when it is certain that Looking will not lead to harmful lies.

We also consider whether Looking is penalized because it signals selfishness. It is possible that people believe that those who would look at the social consequences of honesty would also look at the personal consequences of honesty and therefore selectively follow a rule of honesty when it serves their self-interest. Several supplementary studies suggest this possibility is unlikely. In Studies S1 and S2, we find that the preference for unconditional honesty does not depend on who is affected by honesty. People judge Looking at the social consequences of honesty to be just as unethical as Looking at the selfish, or personal, consequences of honesty. In Study S4, we found that communicators who looked at the social consequences of honesty were perceived as more likely to look at the selfish consequences of 
honesty. However, this inference - that people might condition honesty on whether it benefits the self - did not seem to explain moral judgments. People seem to care much more about whether communicators who are selectively honest will tell harmful, rather than selfish, lies.

Cumulatively, our results suggest that the mechanism underlying the preference for unconditional honesty in communication dilemmas differs from that proposed in prior literature on "cooperation without looking” and quick moral decisions. According to past work, quick, or unconditional, moral decisions are thought to reflect certainty and provide a reliable signal about the likelihood of future desirable behavior (Jordan et al., 2016; Critcher et al., 2013; van de Calseyde et al., 2014; Evans \& Van de Calseyde, 2017; Capraro \& Kuilder, 2016). However, these dynamics have only been studied in the context of right-wrong dilemmas, in which there is a universally valued behavior (e.g., cooperation). In the dilemmatic context examined here, there is no universally desired behavior. The correct behavior (truth-telling or lying) depends on the social consequences that are known at the time of making a decision. Therefore, we posit that uncalculating moral rule-following, in the context of right-wrong and right-right dilemmas, may be rewarded more because it signals information about the immoral acts a decision-maker will not commit, rather than the moral acts they may commit. People care that immoral acts (e.g. defection, harmful lying) are avoided more than they care that the most moral acts are pursued.

\section{Theoretical contributions}

\section{Understanding honesty}

Honesty is one of the most important values to everyday moral decision-making. Yet, our attitudes towards honesty are not easily explained by existing theories of moral judgment. Existing work on deontological intuitions, for example, has primarily been developed to understand the psychology of harm aversion, which as others have noted (e.g., Kahane et al., 
2012, 2018) may be largely unrelated to the psychology of honesty. Our work is the first that we know of to develop a comprehensive theory of honesty, which accommodates the preference for unconditional honesty and the preference for certain lies.

Therefore, this work helps us to understand seemingly hypocritical attitudes towards honesty. People routinely lie in everyday life and recognize that many common lies are prosocial (DePaulo et al., 1996). If people are accepting of prosocial lies, then we might expect education and communication around honesty to reflect these preferences. For example, people might state that honesty is often the best policy but lying is sometimes okay. However people - including parents, teachers, and public leaders - instead tend to invoke absolute language around honesty, endorsing the idea that honesty is always the best policy. Thus, there is an inconsistency in people’s messaging around honesty and actual honest deeds. Given that hypocrisy can be perceived as false signaling, and is often viewed negatively (Effron et al., 2018; Jordan et al., 2017), we might expect that these endorsements of absolute honesty are viewed as cheap talk. However, that is rarely the case. Recent research suggests that taking hypocritical stances on honesty (i.e., endorsing absolute honesty and then telling lies) is often viewed more positively than admissions to moral nuance in the domain of honesty (Huppert et al., 2021). Our current studies add insight into why hypocrisy can be beneficial in the context of honesty in contrast to many other domains. Promoting absolute honesty minimizes the severe moral error of harmful lying.

\section{Normative theories of moral judgment and the preference for moral rules}

Importantly, this work also expands our understanding of moral judgment broadly, beyond the domain of honesty. Specifically, the theory of moral error avoidance helps to explain and bridge conflicting evidence on which normative theories best describe lay moral judgment, 
thereby providing insight into the perceived purpose of moral rules. Different bodies of work claim 1) that people employ and reward deontological impulses (Everett et al., 2016; Greene, 2007; Jordan et al., 2016), and conversely 2) that lay people are best described as intuitive virtueethicists. Whereas deontology places importance on following universal moral rules, virtue ethics places importance on deducing a moral actor's internal character. Lay people operate as intuitive virtue ethicists when they exhibit a preference for moral actors who try to properly weigh conflicting moral concerns in a given situation, rather than follow universal moral principles (Landy \& Uhlman, 2018; Critcher et al., 2020). Our account suggests that both of these normative lenses characterize lay judgments of honesty, albeit in different judgment contexts. When evaluating actions within a given situation, people endorse the selective use of moral principles. For example, they believe that the duty to be honest should be constrained by concerns of harm and prosociality (consistent with a virtue-ethics lens). However, people also believe that it is more moral to follow a categorical policy of honesty and to avoid seeking out information that would put them in situations where moral rules might be questioned (consistent with a deontological lens). In other words, people are intuitive virtue-ethicists when evaluating actions, but deontologists when evaluating policies.

Notably, however, utilitarian logic underlies the deontological preference for honesty as a policy. People believe that following a policy of unconditional honesty reduces overall moral error; that is, absolute honesty reduces overall harm and therefore maximizes overall welfare. This is consistent with yet two more recent perspectives in moral judgment. First, this logic is consistent with work suggesting that many deontological positions are supported by a “consequentialist crutch” (Ditto \& Liu, 2011). Although prior work on the “consequentialist crutch" suggests that people distort their views of what promotes welfare in order to preserve a 
deontological position, our work suggests that people form their deontological beliefs - at least in part - based on an implicit or explicit assessment of the overall welfare implications of different moral policies. The focus on minimizing harm is also consistent with a growing body of work on the centrality of harm aversion in moral judgment (Gray et al.,2012; Schein \& Gray, 2015, 2018). Taken together, our work highlights how the psychology of honesty hinges on multiple perspectives of moral judgment. Moral error avoidance merges the psychology of deontology, utilitarianism (or harm-aversion), and virtue ethics to explain how people can have genuine preferences for both absolute honesty and prosocial lies. Our account also dovetails with recent work on how people manage prosocial risks (Zlatev et al., 2020), which finds that people avoid making the most selfish decisions, rather than making the most prosocial decisions, in order to manager their moral self-regard. Similarly, we find that people reward others who avoid the most immoral decisions, rather than pursue the most moral decisions.

Therefore, our work offers new insight into why we fundamentally value moral rules. Unlike classic deontological philosophers (e.g., Kant, 1785/1959), lay people do not necessarily view moral rules as inviolable, nor do they see rule violations as inherently bad. When rules like honesty - would cause certain harm, rules can, and should, be broken. Yet, rules are still seen as valuable because they minimize overall moral error.

\section{Moral judgment under uncertainty}

Our work also highlights how the time of information acquisition influences moral judgment. Consistent with the doctrine of double effect (Foot, 1967; Cushman, Young, \& Hauser, 2006), we find that communicators are judged as moral when social harm emerges as a

side effect of honest communication (Aquinas, $13^{\text {th }} \mathrm{c} / 1988$ ). It seems that because moral rules are perceived as the optimal strategy to minimize harm a priori, they are not penalized when they 
cause harm post hoc. However, past work on the doctrine of double effect would not necessarily predict that choosing to remain ignorant of potential harm would be rewarded. Thus, our work extends past research finding that people not only judge communicators as moral when social harm emerges as a side effect of honest communication but also when communicators choose to avoid finding out whether telling the truth will cause harm to others.

\section{Practical implications}

Our work also has a number of practical implications. First, our results help us better understand why people reward leaders and other public figures who take absolute stances on honesty. Politicians, leaders, and managers who proclaim that they always tell the truth, rather than admitting to considering the potential consequences of lying versus truth-telling, will be seen as less likely to morally err. Even though leaders likely do consider the consequences of their messaging when choosing how much information to convey (e.g., political or organizational leaders may try to downplay threats in order to avoid panic and chaos), admitting this is likely to be harmful for one’s reputation. Thus, this work helps to explain why people continue to support and elect hypocritical leaders - even if people are comfortable with some lies, they are not comfortable with policies or proclamations that allow for them.

Understanding this discrepancy also has implications for moral education. If people worry that nuanced, or conditional moral stances may lead to large moral errors, they are unlikely to discuss exceptions and trade-offs to moral rules with followers, students and children. Therefore, moral education is likely to be limited to formalized; rigid rules and will lack rigorous consideration of ambiguous moral situations. Examining ways to have effective conversations around moral rules, including when exceptions to a rule can be prosocial, is an important, and underexplored, avenue for future research. 
Our account also deepens our understanding of people's ambivalence towards using algorithms (i.e., unconditional rules; Dietvorst, Simmons, \& Massey, 2015). People tend to object to decision-making algorithms (Dietvorst \& Bartels, 2021) and to human decision-makers who follow uniform rules for making complex moral decisions, such as those involving punishment (White, Levine, \& Kristal, 2021). People fear that these approaches will miss important nuances that are necessary for handling individual cases fairly. However, our account suggests that when considering how to handle multiple cases, algorithms may be more attractive. That is, people may be wary of using algorithms when considering how those algorithms impact individual decisions, but at the same time, they may also appreciate that algorithms help minimize moral errors across cases. Future research should examine how preferences for algorithms shift when evaluating their use for single versus multiple decisions.

\section{Roadmap for future research}

\section{Understanding asymmetric judgments}

More work is needed to fully understand the nature and consequences of moral error avoidance. First, future work should seek to understand what drives the asymmetric costs of harmful truths and harmful lies. Though our work establishes that the cost asymmetry influences the preference for unconditional honesty, it is not clear why harmful truths are a less costly error than harmful lies. One possibility is that two moral violations are simply worse than one. Harmful lies reflect a violation of both honesty and benevolence, whereas prosocial lies and harmful truths simply reflect different tradeoffs. It is possible that a combination of moral violations is always seen as more unethical than a single violation, despite causing identical harm. 
It is also possible that people think lying is more likely to cause harm than truth-telling is. That is, people may believe that there is an asymmetry in the frequency which harmful lies and harmful truths occur, which could also produce a preference for unconditional honesty. If people do not believe that truth-telling leads to harm particularly often, but that lying does, a policy of unconditional honesty minimizes overall moral error (i.e., harm). We control for these inferences in several of our studies (e.g., Studies 1 \& 3) by clarifying that truth-telling and lying were equally likely to lead to prosocial versus harmful outcomes. Therefore, it seems unlikely that beliefs about the frequency with which truth-telling leads to harm account for the full range of our effects. Nonetheless, it is possible that these beliefs lead to even stronger preference for absolute honesty in the real world. Furthermore, these beliefs would be consistent with the “social heuristics hypothesis” (Rand, et al., 2014), which suggests that because cooperation is typically advantageous, we have developed intuitive heuristics that favor it that are deployed even in settings where cooperation is no longer advantageous (i.e., one-shot anonymous interactions in the laboratory). Similarly, people may believe that honesty is typically associated with welfare-maximization, leading people to favor honesty as a general heuristic. Future work should investigate this possibility.

\section{Understanding the communicator perspective}

We also encourage research to explore whether communicators anticipate others’ preference for unconditional honesty. Are communicators attuned to the social rewards associated with unconditional honesty? If so, does this lead them to engage in unconditional honesty? Our lived experiences with honesty and dishonesty make this seem unlikely. Nonetheless, future work should investigate this possibility. It is possible that communicators' honesty decisions are influenced by the degree to which they focus on the reputational benefits 
accorded by observers, or the potential relational costs accorded by the targets of harmful truths. Three of our supplemental studies provide initial insight into the frequency with which communicators engage in unconditional honesty (see SOM 2.2, 2.3, and 2.6). Across these studies, the majority of communicators chose to be honest without looking at the consequences of honesty. Furthermore, the preference for unconditional honesty was marginally stronger when the harm of honesty was more salient (see Study S3, and Table S27 for a summary). However, we did not directly manipulate the observability of these decisions. Manipulating whether or not communicators are aware that targets or external observers are judging their decision strategy will be helpful for understanding how communication decisions are influenced by expected reputational benefits.

\section{Unconditional honesty in the real world}

Across all of our studies, unconditional honesty (HWOL) and Looking were operationalized as distinct, mutually exclusive decision strategies. In natural conversation, however, it may be possible to integrate these approaches in order to hedge against the relational costs of harmful truths. For example, consider the case of a friend who asks how an ill-fitting outfit looks (as in Study 2). While a communicator could immediately respond by stating the truth (HWOL) or by seeking out information about whether the friend could change (Look), they may also use a more integrative strategy. For example, they may choose to start with a prosocial lie - responding that their friend looks great - and then ask for more information (i.e., casually asking if the friend has any other outfits they were considering wearing). If a communicator learns their friend cannot change, the decision tree ends benevolently at a prosocial lie rather than a harmful truth that would have resulted from unconditional honesty. On the other hand, if the friend can change, the communicator can follow their prosocial lie with a helpful truth by 
recommending that a different outfit would be even better. This strategy, "Prosociality plus Looking," prioritizes benevolent communication by maximizing the welfare of targets across cases. Importantly, this strategy also ensures that harmful lies are not told. Future research should investigate whether people employ hybrid approaches in naturalistic settings and how these approaches are judged. The results of Study 4 suggest that communication strategies that entail precomitting to prosociality will be seen at least as positively as ones that involve information-seeking.

\section{Moral error management across domains and cultures}

Finally, future research ought to examine how the theory of moral error management applies to other moral domains. In Study 4, we found that although people judged unconditional honesty to be more ethical than looking at the consequences of one's honesty, people did not judge unconditional prosociality in the same way. More research is needed to understand why. Both unconditional prosociality and unconditional honesty minimize moral error; both strategies ensure that harmful lies will not be told. However, it is possible that looking for information about the consequences of a moral behavior signals greater moral flexibility than seeking out information about whether another principle is violated (Kreps \& Monin, 2014). As a result, seeking out information about consequences may activate concerns about moral errors to a greater extent.

When resolving dilemmas involving fairness, people may also have the opportunity to seek out information about the consequences of their decisions. Following a simple rule of equality would lead a decision-maker to split a resource equally across beneficiaries. Although this may be conceptualized as fair when beneficiaries have the same starting allocation, giving beneficiaries allocations that equalize beneficiaries' final endowments may be optimal when 
initial allocations (i.e., their needs) differ. That is, the fairest decision may depend on the ultimate consequences of one’s allocation strategy. However, giving less to more needy beneficiaries is the most unfair action; it represents the greatest moral error. Therefore, similar to how people value unconditional honesty, people may value equality because it prevents this error. Future work should test this.

Moral error management may also be more or less prominent in different cultures. People in Eastern cultures tend to have a more holistic thought style whereas people in Western cultures tend to have a more analytic thought style (Nisbett et al., 2001). These differences in cognition may have implications for how people reason about moral dilemmas and whether they employ moral error management in their decision-making process. In Western cultures, an emphasis is placed on principles and logic, so we might expect that an analytic thought style leads to a preference for absolute, categorical rules. In contrast, cultures that employ a holistic thought style may actually value Looking as a decision strategy because it prioritizes the interpersonal relationships that are central to their culture. Since Eastern cultures place more emphasis on the interconnectedness of people and relationships between objects, the perceived costs of telling a harmful lie versus a harmful truth may be less asymmetric than they are in Western cultures. That is, because of the potential relational damage that could occur, telling a harmful truth may be viewed as equally detrimental as telling a harmful lie. Therefore, in societies that employ holistic thought styles, we might expect an attenuation, or reversal of, the preference for unconditional rule honesty.

\section{Conclusion}

People simultaneously claim that honesty is the best policy and that prosocial lying is ethical. The present research develops and tests a theory to explain these seemingly incompatible 
beliefs. People endorse unconditional honesty because it minimizes moral error overall, even though it prevents people from telling moral, prosocial lies. Moral error management helps to explain the psychology of honesty, as well as moral rules more broadly. We encourage future work to test this theory across situations, domains, and cultures. 


\section{References}

Abbey, A. (1982). Sex differences in attributions for friendly behavior: Do males misperceive females' friendliness?. Journal of Personality and Social Psychology, 42(5), 830.

Abbey, A., \& Melby, C. (1986). The effects of nonverbal cues on gender differences in perceptions of sexual intent. Sex Roles, 15(5-6), 283-298.

Anderson, N. H. (1968). Likableness ratings of 555 personality-trait words. Journal of Personality and Social Psychology, 9(3), 272.

Anderson, R. A., Ruisch, B. C., \& Pizarro, D. A. (working paper). On the highway to hell: Slippery slope perceptions in judgments of moral character. http://benruisch.com/wpcontent/uploads/2021/05/Slippery-Slope-Paper-8-8-20.pdf

Aquinas, Thomas (13 ${ }^{\text {th }}$ c.). Summa theologica II-II, q. 64, art. 7,“of Killing”. In W. P. Baumgarth and R. J. Regan (Eds.), On Law, Morality, and Politics (pp. 226-227). Hackett Publishing Company.

Barasch, A., Levine, E. E., Berman, J. Z., \& Small, D. A. (2014). Selfish or selfless? On the signal value of emotion in altruistic behavior. Journal of Personality and Social Psychology, 107(3), 393-413.

Blanton, B. (2005). Radical honesty: How to transform your life by telling the truth. Stanley, VA: Sparrowhawk Publications.

Boles, T. L., Croson, R. T., \& Murnighan, J. K. (2000). Deception and retribution in repeated ultimatum bargaining. Organizational Behavior and Human Decision Processes, 83(2), 235-259. 
Capraro, V., \& Kuilder, J. (2016). To know or not to know? Looking at payoffs signals selfish behavior, but it does not actually mean so. Journal of Behavioral and Experimental Economics, 65, 79-84.

Critcher, C. R., Helzer, E. G., \& Tannenbaum, D. (2020). Moral character evaluation: Testing another’s moral-cognitive machinery. Journal of Experimental Social Psychology, 87, Article 103906.

Critcher, C.R., Inbar, Y., \& Pizarro, D.A. (2013). How quick decisions illuminate moral character. Social Psychological and Personality Science, 4(3), 308-315.

Cushman, F., Young, L., \& Hauser, M. (2006). The role of conscious reasoning and intuition in moral judgment: Testing three principles of harm. Psychological Science, 17, 1082-1089.

Dalio, R. (2017). Principles: Life and work. Simon and Schuster.

Dietvorst, B. J., \& Bartels, D. M. (2021). Consumers object to algorithms making morally relevant tradeoffs because of algorithms’ consequentialist decision strategies. Journal of Consumer Psychology.

Dietvorst, B. J., Simmons, J. P., \& Massey, C. (2015). Algorithm aversion: People erroneously avoid algorithms after seeing them err. Journal of Experimental Psychology: General, 144(1), 114.

DePaulo, B. M., Kashy, D. A., Kirkendol, S. E., Wyer, M. M., \& Epstein, J. A. (1996). Lying in everyday life. Journal of Personality and Social Psychology, 70(5), 979.

Ditto, P. H. \& Liu, B. S. (2011). What Dilemma? Moral evaluation shapes factual belief. Social Psychological and Personality Science, 4(3), 316-323. 
Effron, D. A., O’Connor, K., Leroy, H., \& Lucas, B. J. (2018). From inconsistency to hypocrisy: When does "saying one thing but doing another" invite condemnation?. Research in Organizational Behavior, 38, 61-75.

Evans, A. M., \& Van de Calseyde, P. P. (2017). The effects of observed decision time on expectations of extremity and cooperation. Journal of Experimental Social Psychology, 68, $50-59$.

Everett, J. A., Pizarro, D. A., \& Crockett, M. J. (2016). Inference of trustworthiness from intuitive moral judgments. Journal of Experimental Psychology: General, 145(6), 772787.

Faul, F., Erdfelder, E., Buchner, A., \& Lang, A.-G. (2009). Statistical power analyses using G*Power 3.1: Tests for correlation and regression analyses. Behavior Research Methods, 41, 1149-1160.

Foot, P. (1967). The problem of abortion and the doctrine of double effect. Oxford Review, 5, 515.

Gino, F. \& Galinsky, A. D. (2012). Vicarious dishonesty: When psychological closeness creates distance from one’s moral compass. Organizational Behavior and Human Decision Processes, 119(10, 15-26.

Gino, F., \& Schweitzer, M. E. (2008). Blinded by anger or feeling the love: how emotions influence advice taking. Journal of Applied Psychology, 93(5), 1165.

Gneezy, U. (2005). Deception: The role of consequences. American Economic Review, 95(1), 384-394. 
Goodwin, G. P., Piazza, J., \& Rozin, P. (2014). Moral character predominates in person perception and evaluation. Journal of Personality and Social Psychology, 106(1), 148168.

Gray, K., Schein, C., \& Ward, A. F. (2014). The myth of harmless wrongs in moral cognition: Automatic dyadic completion from sin to suffering. Journal of Experimental Psychology: General, 143(4), 1600.

Gray, K., Waytz, A., \& Young, L. (2012). The moral dyad: A fundamental template unifying moral judgment. Psychological Inquiry, 23(2), 206-215.

Greene, J. D. (2007). Why are VMPFC patients more utilitarian? A dual-process theory of moral judgment explains. Trends in Cognitive Sciences, 11(8), 322-323.

Greene, J. D., Sommerville, R. B., Nystrom, L. E., Darley, J. M., \& Cohen, J. D. (2001). An fMRI investigation of emotional engagement in moral judgment. Science, 293(5537), 2105-2108.

Harris, A. (2013). Distributed Leadership: Friend or Foe? Educational Management Administration \& Leadership, 41(5), 545-554.

Haselton, M. G., \& Buss, D. M. (2000). Error management theory: a new perspective on biases in cross-sex mind reading. Journal of Personality and Social Psychology, 78(1), 81.

Hayes, A. F. (2013). Introduction to mediation, moderation, and conditional process analysis: A regression-based approach. Guilford Press.

Hildreth, J. A. D., \& Anderson, C. (2018). Does loyalty trump honesty? Moral judgments of loyalty-driven deceit. Journal of Experimental Social Psychology, 79, 87-94. 
Hildreth, J. A.D., Gino, F., \& Bazerman, M. (2016). Blind loyalty? When group loyalty makes us see evil or engage in it. Organizational Behavior and Human Decision Processes, 132, 16-36.

Hoffman, M., Yoeli, E., \& Nowak, M.A. (2015). Cooperate without looking: Why we care what people think and not just what they do. Proceedings of the National Academy of Sciences, 1-6. DOI:10.1073/pnas.1417904112.

Hofmann, W., Wisneski, D. C., Brandt, M. J., \& Skitka, L. J. (2014). Morality in everyday life. Science, 345(6202), 1340-1343.

Huppert, E., Herzog, N., Levine, E.E., Landy, J. (2021). Being dishonest about dishonesty The social benefits of taking absolute (but hypocritical) moral stances. Working paper.

Jampol, L., \& Zayas, V. (2021). Gendered White Lies: Women Are Given Inflated Performance Feedback Compared With Men. Personality and Social Psychology Bulletin, 47(1), 5769.

Johnson, D. D. (2009). The error of God: Error management theory, religion, and the evolution of cooperation. In Games, groups, and the global good (pp. 169-180). Springer: Berlin, Heidelberg.

Jordan, J.J., Hoffman, M., Nowak, M.A., \& Rand, D.G. (2016). Uncalculating cooperation is used to signal trustworthiness. Proceedings of the National Academy of Sciences, 113(31), 8658-8663.

Jordan, J., Sommers, R., Bloom, P., \& Rand, D. G. (2017). Why do we hate Hypocrites? Evidence for a Theory of False Signaling. Psychological Science, 28(3), 356-368. 
Kahane, G., Everett, J. A., Earp, B. D., Caviola, L., Faber, N. S., Crockett, M. J., \& Savulescu, J. (2018). Beyond sacrificial harm: A two-dimensional model of utilitarian psychology. Psychological Review, 125(2), 131.

Kahane, G., Wiech, K., Shackel, N., Farias, M., Savulescu, J., \& Tracey, I. (2012). The neural basis of intuitive and counterintuitive moral judgment. Social Cognitive and Affective Neuroscience, 7(4), 393-402.

Kant, I. (1959). Foundations of the metaphysics of morals (L. W. Beck, Trans.) Bobbs-Merrill Company. (Original work published 1785)Kidder, R. M. (1995). How good people make tough choices. New York: Morrow.

Kohlberg, L. 1971. Stages of moral development as a basis for moral education. In C. M. Beck, B. S. Crittenden \& E. V. Sullivan (Eds.), Moral education: Interdisciplinary approaches: 23-92. Toronto, Canada: University of Toronto Press.

Kreps, T. A., \& Monin, B. (2014). Core values versus common sense: Consequentialist views appear less rooted in morality. Personality and Social Psychology Bulletin, 40(11), 15291542.

Landy, J. F., \& Uhlmann, E. L. (2018). Morality is personal. Atlas of Moral Psychology, 121.

Lee, J.J., Hardin, A. E., Parmar, B., \& Gino, F. (2019). The interpersonal costs of dishonesty: How dishonest behavior reduces individuals’ ability to read other’ emotions. Journal of Experimental Psychology: General, 148(9), 1557-1574.

Levine, E.E. (2021). Community standards of deception: Deception is perceived to be ethical when it prevents unnecessary harm. https://doi.org/10.31234/osf.io/g5trb 
Levine, E. E., Barasch, A., Rand, D., Berman, J. Z., \& Small, D. A. (2018). Signaling emotion and reason in cooperation. Journal of Experimental Psychology: General, 147(5), 702719.

Levine, E. E., \& Lupoli, M. J. (2021). Prosocial Lies: Causes and Consequences. Current Opinion in Psychology, 43, 335-340.

Levine, E.E. \& Munguia Gomez, D. (2020). “I’m just being honest.” When and why honesty enables helping versus harming behaviors. Journal of Personality and Social Psychology, 120(1): 33-56.

Levine, E.E. \& Schweitzer, M.E. (2014). Are liars ethical? On the tension between benevolence and honesty. Journal of Experimental Social Psychology, 53, 107-117.

Levine, E.E. \& Schweitzer, M.E. (2015). Prosocial lies: when deception breeds trust. Organizational Behavior and Human Decision Processes, 126, 88-106.

Lewis, M., \& Saarni, C. (1993). Lying and deception in everyday life. The Guilford Press.

Lipsey, M. W. \& Wilson, D. B. (2001). Practical meta-analysis. Sage Publications, Inc.

Mazar, N., Amir, O., \& Ariely, D. (2008). The Dishonesty of Honest People: A Theory of SelfConcept Maintenance. Journal of Marketing Research, 45(6), 633-644.

Mazar, N.\& Ariely, D. 2006). Dishonesty in Everyday Life and its Policy Implications. Journal of Public Policy and marketing, 25(1), 117-126.

Nisbett, R. E., Peng, K., Choi, I., \& Norenzayan, A. (2001). Culture and systems of thought: Holistic versus analytic cognition. Psychological Review, 108(2), 291-310.

Pascal, B. (2008). Pensées and other writings (A. Levi, Ed.; H. Levi, Trans.). Oxford University Press. (Original work published 1669)

Planalp, S., Rutherford, D. K., \& Honeycutt, J. M. (1988). Events that increase 
uncertainty in personal relationship: II. Replication and extension. Human Communication Research, 14(4), 516-547.

Rand, D. G., Peysakhovich, A., Kraft-Todd, G. T., Newman, G. E., Wurzbacher, O., Nowak, M. A., \& Greene, J. D. (2014). Social heuristics shape intuitive cooperation. Nature Communications, 5(1), 1-12.

Royzman, E., \& Baron, J. (2002). The preference for indirect harm. Social Justice Research, 15, 165-184.

Schein, C., \& Gray, K. (2015). The unifying moral dyad: Liberals and conservatives share the same harm-based moral template. Personality and Social Psychology Bulletin, 41(8), 1147-1163.

Schein, C. \& Gray, K. (2018). The Theory of Dyadic Morality: Reinventing Moral Judgment by Redefining Harm. Personality and Social Psychology Review, 22(1), 32-70.

Schweitzer, M. E., Hershey, J. C., \& Bradlow, E. T. (2006). Promises and lies: Restoring violated trust. Organizational Behavior and Human Decision Processes, 101(1), 1-19.

Shafir, E. \& Tversky, A. (1992). The disjunction effect in choice under uncertainty. Psychological Science, 3(5), 305-310. DOI: 10.1111/j.1467-9280.1992.tb00678.x

Talwar, V., Murphy, S. M., \& Lee, K. (2007). White lie-telling in children for politeness purposes. International Journal of Behavioral Development, 31(1), 1-11.

Tyler, J. M., Feldman, R. S., \& Reichert, A. (2006). The price of deceptive behavior: Disliking and lying to people who lie to us. Journal of Experimental Social Psychology, 42(1), 6977.

Weisel, O., \& Shalvi, S. (2015). The collaborative roots of corruption. Proceedings of the National Academy of Sciences, 112(34), 10651-10656. 
White, M., Levine, E.E., Kristal, A. Rules are meant to be broken: The effects of consistency and discretion on interpersonal trust. Working paper.

Wiltermuth, S. S. (2011). Cheating more when the spoils are split. Organizational Behavior and Human Decision Processes, 115(2), 157-168.

Van de Calseyde, P. P., Keren, G., \& Zeelenberg, M. (2014). Decision time as information in judgment and choice. Organizational Behavior and Human Decision Processes, 125(2), 113-122.

Van Zant, A. B. \& Moore, D. A. (2015). Leaders’ use of moral justifications increases policy support. Psychological Science, 26 (6), 934-943.

Zhang, T., Gino, F., \& Margolis, J. D. (2018). Does “could” lead to good? On the road to moral insight. Academy of Management Journal, 61(3), 857-895.

Zlatev, J. J. (2019). I may not agree with you, but I trust you: Caring about social issues signals integrity. Psychological Science, 30(6), 880-892.

Zlatev, J. J., Kupor, D. M., Laurin, K., \& Miller, D. T. (2020). Being “good” or “good enough”: Prosocial risk and the structure of moral self-regard. Journal of Personality and Social Psychology, 118(2), 242. 